\title{
Alternative and sustainable heat production for drinking water needs in a subarctic climate (Nunavik, Canada): borehole thermal energy storage to reduce fossil fuel dependency in off-grid communities.
}

\author{
Nicolò Giordano ${ }^{1}$, Jasmin Raymond ${ }^{1}$ \\ ${ }^{1}$ Institut national de la recherche scientifique - Centre Eau Terre Environnement, 490 Rue de la Couronne, G1K 9A9, \\ Québec (QC), Canada
}

\section{Corresponding author:}

Nicolò Giordano, nicolo.giordano@ete.inrs.ca, ORCID 0000-0002-0747-444X

Key words: solar-geothermal, TRNSYS, FEFLOW, Arctic, groundwater, life-cycle cost analysis

\section{Highlights}

- First-time design of borehole thermal energy storage in a subarctic climate

- Best scenarios provide $50 \%$ solar fraction and $60 \%$ heat recovery at the $3^{\text {rd }}$ year

- Annual savings of 70001 of diesel and 19 tonnes of equivalent $\mathrm{CO}_{2}$ are achieved

- A novel type of borehole connection reduces advection heat loss by $60 \%$

- Underground storage is a key technology towards energy and food security in the Arctic

\begin{abstract}
The development of renewable energy technologies in the Arctic faces technical barriers mainly related to extremely cold temperature. Moreover, storage issues to bridge the gap between supply and demand are more compelling than in temperate climates. Can underground thermal energy storage be efficiently used in such a cold environment to offer a viable seasonal storage alternative? This working hypothesis was tested by designing and simulating for the first time a borehole thermal energy storage facility in a subarctic climate. A system comprising a $1000 \mathrm{~m}^{2}$ gross solar area and one hundred 30-m-deep borehole heat exchangers was simulated in TRNSYS to cover part of the heating demand of a pumping station that supplies drinking water in Kuujjuaq (Northern Québec, Canada). The Nunavik capital is characterized by more than 8000 heating degree days below $18{ }^{\circ} \mathrm{C}$ and average spring-summer solar radiation of $4.6 \mathrm{kWh} \mathrm{m}^{-2} \mathrm{~d}^{-1}$. Despite the presence of discontinuous scattered permafrost in the area, the study site is free of frozen ground, likely due to a talik that developed around a nearby lake. A number of scenarios reveal that solar fraction of 45 to $50 \%$ and heat recovery of more than $60 \%$ can be achieved by the $3^{\text {rd }}$ year of operation, resulting in annual savings of 70001 of regular diesel consumption. A 50-years life-cycle cost analysis demonstrates that a specific incentive program can guarantee similar net present cost and levelized cost of energy compared to the current dieseldependent situation, or better if electricity comes from renewable source. An additional $10 \%$ loss of thermal energy occurs when groundwater advection is a factor. FEFLOW simulations demonstrate that square-shaped storage together with a newly-proposed borehole connection design can reduce advection heat loss by $60 \%$ and improve the overall performance of the system. This work validates the technical viability of underground thermal energy storage in subarctic climates and indicates it could help reduce fossil fuel consumption in
\end{abstract}


remote arctic regions across the world. Moreover, the novel type of borehole connection designed for this study can be useful in seasonal storage systems facing low heat recovery due to groundwater flow, regardless of climate.

\section{Introduction}

Over the last 20 years, energy has been a subject of tremendous interest to the Arctic Council due to the possibility of discovering new hydrocarbon resources, as polar ice caps melt. However, a major concern of all eight member states is the fact that remote villages rely heavily on fossil fuels for both electricity and heat generation [1,2]. The Arctic comprises almost 1500 off-grid settlements hosting more than 1.6 million people in Canada, United States, Russia, Norway and Denmark, and facing critical challenges related to climate change that are only expected to worsen in the future [3]. Several projects in the last decades have studied the possible contribution of renewable energy sources in these extreme natural environments [4-6]. Technical, logistical and regulatory problems are commonly the most important barriers to the exploitation of renewable sources such as hydro, solar, geothermal, wind, and tidal [3,5]. Therefore, research and development (R\&D) and demonstration projects are vital across the globe to envision sustainable Arctic development in the near future. Access to clean and local energy in remote communities can fulfil growing electricity and heating needs without further risk to an environment that is highly vulnerable to the consequences of global warming $[7,8]$. Moreover, clean local energy can be a powerful tool for autochthonous populations to affirm their autonomy and foster sustainable development through community energy plans [9].

Canada has the second largest population living in subarctic and arctic remote communities with approximately 200000 people, 35000 of them in Québec [10]. Kuujjuaq is the regional capital of Nunavik, the Inuit territory in Québec north of the 55 $5^{\text {th }}$ parallel. Nunavik inhabitants numbered 12300 in 2011 (2375 in Kuujjuaq), and the population growth rate has been $40 \%$ since 2000 [11]. All the villages rely on fossil fuels to produce both electricity and heat. Diesel power plants provide electricity with production prices ranging between 0.5 and 1.1 USD kWh ${ }^{-1}$, with Kuujjuaq averaging 0.6 (exchange rate CAD/USD 1.34). For comparison, in less remote regions of Québec, the cost of on-grid (hydro) and off-grid (fossil) electricity production is about 0.02 and $0.3 \mathrm{USD} \mathrm{kWh}^{-1}$, respectively $[12,13]$. Space heating (SH) and domestic hot water (DHW) are commonly provided autonomously with a furnace in each building, and the subsidised cost of diesel in Nunavik was 1.5 USD $^{-1}$ in 2018 [14]. The Government of Québec guarantees subsidies to residents for both electricity and diesel: the subsidised cost of electricity is currently $0.04 \mathrm{USD} \mathrm{kWh}^{-1}$ until a monthly energy consumption of $900 \mathrm{kWh}$ and then $0.28 \mathrm{USD} \mathrm{kWh}^{-1}$; the subsidy on the diesel is $0.30 \mathrm{USD} \mathrm{l}^{-1}[13,14]$. In Nunavik, total subsidies amount to approximately 9 million USD $\mathrm{y}^{-1}$ and 56 million USD $\mathrm{y}^{-1}$, respectively. In light of this situation, developing new technologies to meet the energy needs of these communities is of paramount importance to reduce the high financial cost and environmental impacts of long and difficult fuel shipments by boat. Renewable energy is a promising avenue, and detailed studies are being carried out to evaluate the possible use of local geothermal resources to meet provincial government's sustainable development objectives and reduce greenhouse gas emissions (GHG) [15]. 
Thermal energy storage can be performed by exploiting the heat of thermochemical reaction, the latent heat of phase change and the sensible heat: the latter works by increasing/decreasing the temperature of materials such as water, thermal oils, molten salts or geological media [16-19]. Underground thermal energy storage (UTES) systems mainly benefit from their low specific cost-to-storage-capacity ratio [20,21] and the large availability of the materials. Among the UTES, borehole thermal energy storage (BTES) stores and retrieves heat from the subsurface by means of shallow borehole heat exchangers (BHE). It is particularly recommended for small to moderate energy needs where groundwater resources are scarce and hydrogeological conditions are unfavourable for pumping water [17]. Several plants have been built since the 1980s in response to the oil crisis of the early 1970s, with the most active countries in R\&D being France [22], Sweden [23,24] and Switzerland [25]. In the last few decades, Germany has designed and tested a number of central solar heating plants with different types of seasonal storage [26,27]. Other countries such as China [28], Canada [29], Denmark [30], Italy [31-33] and Czech Republic [34] later contributed to the development of this promising technology towards the important target of $100 \%$ renewable world [35]. UTES are therefore a mature technology that can help exploit solar energy throughout the whole heating season, thus bridging the gap for long-term seasonal storage. The solar fraction (SF) typically exceeds $50 \%$ and in some cases is over $90 \%$ $[28,29,36]$. However, one of the main concerns when dealing with these systems is the very high outlay for the plant, due to the cost of solar collectors and drilling activities, with typical total BHE lengths in the range of 2000 to $5000 \mathrm{~m}$. System optimization, process integration analysis and life-cycle cost assessment are useful tools to mitigate the financial hurdle and help spread the technology among arctic communities in Canada and worldwide. As an example, researchers have demonstrated that significant savings can be obtained by a focused optimization of each element without affecting the overall performance, sometimes even increasing heat recovery (HR; e.g. [37,38]). Others have developed tools and methodologies for process integration to determine the benefits provided by energy storage technology and evaluating its performance from a stakeholder's perspective ([39] and references therein). Still others carried out life-cycle cost analyses of integrating seasonal storage into district heating networks by taking into account economic and environmental boundary conditions (e.g. [20,40]), or by focussing on the most appropriate type, scale and number [41] or size of the storage [42] for optimal integration into community energy systems. Renewable energy production of both electricity and heat appears feasible in the Arctic, but energy storage remains the most important and common problem among all intermittent renewable resources. Thermal energy storage could be the key to overcoming fossil fuel dependency, which can be considered as a consequence of the difficulty of harvesting and storing energy from renewable sources [17]. In particular, the authors believe that seasonal energy storage will be a strategic technology to increase energy and food security $[43,44]$ in the off-grid communities of circum-arctic countries.

With this in mind, seasonal BTES was studied as a possible alternative for solving the storage issues of intermittent renewable energy systems in the Arctic, by expanding solar capacity and reducing diesel consumption to heat buildings [45] and to produce food and drinking water. The hypothesis was that BTES can be energy efficient in near-freezing subsurface conditions. Despite several demonstrations in different 
climate contexts around the world, to the best of our knowledge a BTES system has never been tested in a subarctic environment, where the space heating demand is characterized by more than 8000 heating degree days below $18{ }^{\circ} \mathrm{C}\left(\mathrm{HDD}_{18}\right)$. Challenges at high latitudes have already been tackled in Europe [42,46], but the same latitudes in North America are colder. Canadian climate normals from 1981-2010 indicate 8520 HDD 18 in Kuujjuaq (Québec, $58^{\circ} \mathrm{N}$ ), compared to $4930 \mathrm{HDD}_{18}$ in Okotoks (Alberta, 50 ${ }^{\circ} \mathrm{N}$ ) [29] and $6580 \mathrm{HDD}_{18}$ in Whitehorse (Yukon Territory, $60^{\circ} \mathrm{N}$ ) [47] where a pre-feasibility study of a BTES system for a residential district was conducted in 2014 [48]. In Scandinavia, however, Luleå (Sweden, 65 N) has $6980 \mathrm{HDD}_{18}$ [49] and Helsinki (Finland, $60^{\circ} \mathrm{N}$ ) has $4600 \mathrm{HDD}_{18}$ [36]. To date, only GSHP performances in arctic to subarctic climates have been thoroughly studied and tested in Alaska (e.g. Fairbanks $\left(64^{\circ} \mathrm{N}\right)$ has $7500 \mathrm{HDD}_{18}$ ) and Northern China ([50,51] and references therein). A few additional studies for GSHP with horizontal heat exchangers have recently been carried out in Nunavik [52,53]. Different types of heat storage have been tested in some residential applications in Alaska (e.g. water tank and pit storages), but there is a clear lack of knowledge about TES performances in such a cold climate [45], with particular reference to BTES. Ahead of demonstration plants, BTES operations need to be simulated based on local weather and subsurface conditions to reduce uncertainty and push the limit of geothermal systems further north, helping determine how to cope with unbalanced heating loads, near-freezing ground conditions and local groundwater flow. It has been widely demonstrated that GSHPs can benefit from groundwater flow around BHEs (e.g. [54,55]). On the other hand, advection is one of the most negative factors affecting the HR of underground storage systems. BTES performance influenced by groundwater flow was addressed by some recent studies on synthetic models [56] and operating plants [34,57-59]. However, the optimization of borehole disposition with regards to groundwater flow direction has never been studied.

To partially fill these gaps, a BTES system was designed and simulated in the subarctic environment of Kuujjuaq. The chosen target is the drinking water facility that currently relies on diesel to heat the water and prevent freezing along the piped aqueduct. Drinking water is a major challenge in Nunavik $[60,61]$ and any energy and financial savings related to its production would be critical for northern communities. The objectives of the present study are:

(1) To anticipate the thermal response of a BTES system in a subarctic climate, using Kuujjuaq as a reference case. The design and optimization of the system are carried out by means of dynamic TRNSYS simulations [62]; 11 scenarios are developed to reach a SF of $50 \%$ based on a preliminary study by [63].

(2) To evaluate the impact of groundwater flow on BTES performance by modelling the thermohydrogeological behaviour of the underground storage system with FEFLOW [64], which allows advection heat loss to be quantified, and by optimizing the storage through a novel type of borehole connection that enables higher HR.

After presenting the geographic, climatic and geologic setting of the study site, the BTES design is described and details of the TRNSYS and FEFLOW models are displayed. Results of the simulations are used to 
demonstrate the performance of the system and to highlight the economic and environmental advantages with respect to the town's current diesel-dependent situation via a 50-years life-cycle cost analysis. The influence of groundwater flow on the HR is discussed to draw attention to the benefits of the novel type of circulation, which can also be successfully deployed in southern climates. Finally, conclusions are drawn to promote the construction of demonstration plants in the Arctic.

\section{Geographic, climatic and geological setting}

Kuujjuaq $\left(58.10^{\circ} \mathrm{N},-68.42^{\circ} \mathrm{E}\right)$ is the largest of the 14 Inuit communities along the coasts of the Ungava Peninsula, which is surrounded by Hudson Bay (W), Hudson Strait (N) and Ungava Bay (W; Fig. 1). Kuujjuaq has a subarctic climate with an average annual air temperature of $-5.8^{\circ} \mathrm{C}$. The mean solar radiation from April to September is $4.6 \mathrm{kWh} \mathrm{m}^{-2} \mathrm{~d}^{-1}$ and the mean temperature from October to March is $-15^{\circ} \mathrm{C}$ [47] (Fig. 2). A warming trend was measured from $1990\left(-7^{\circ} \mathrm{C}\right)$ to $2010\left(-3.5^{\circ} \mathrm{C}\right)$ [60]. The presence of discontinuous but widespread permafrost is reported in the region [65] and its presence is strongly dependent on local geological conditions [61].
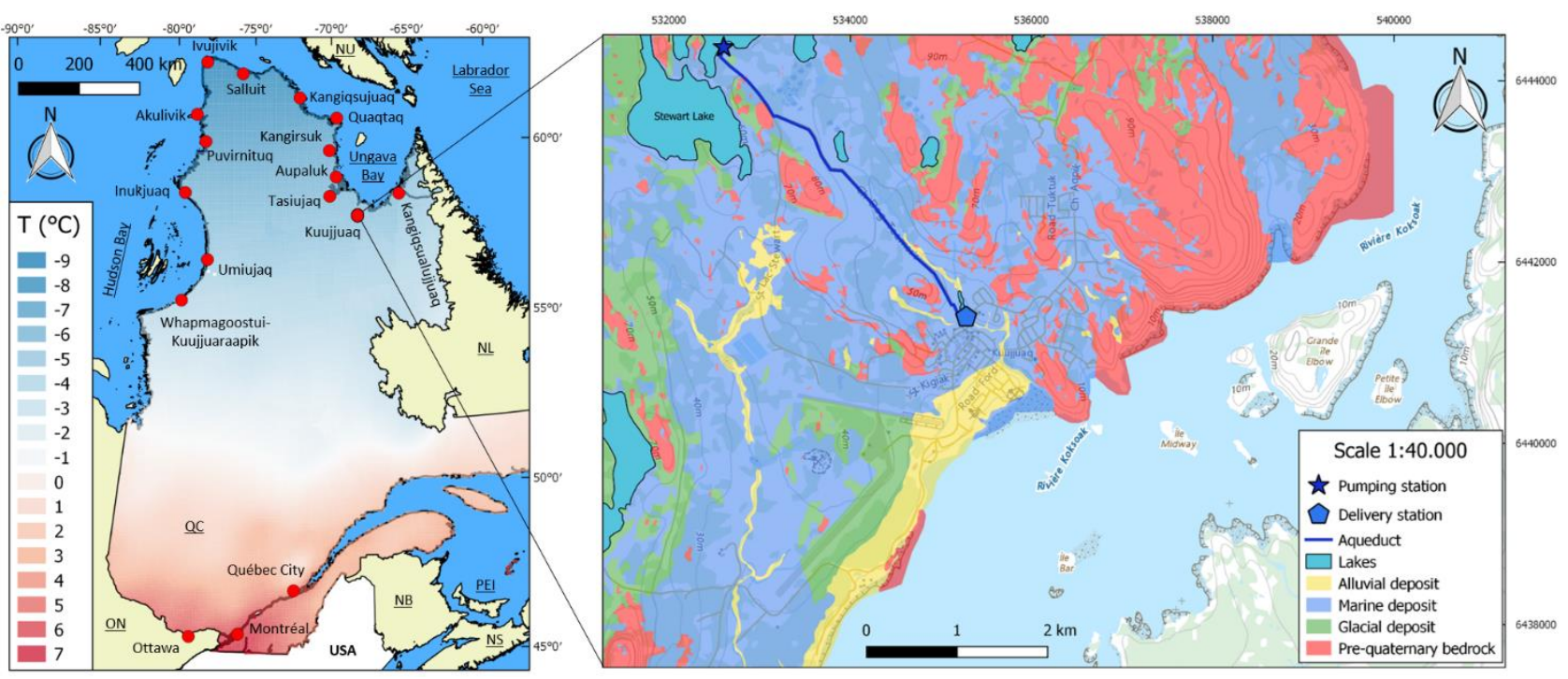

Figure 1 - Left: mean annual air temperature of Québec (coordinates in WGS84; ON: Ontario, QC: Québec, NB: New Brunswick, NL: Newfoundland and Labrador, NU: Nunavut, PEI: Prince Edward Island, NS: Nova Scotia). Right: Quaternary map of the study area (modified from [60]; coordinates in NAD83/UTM Zone 19N) showing the location of the pumping station, the aqueduct and the delivery station. 


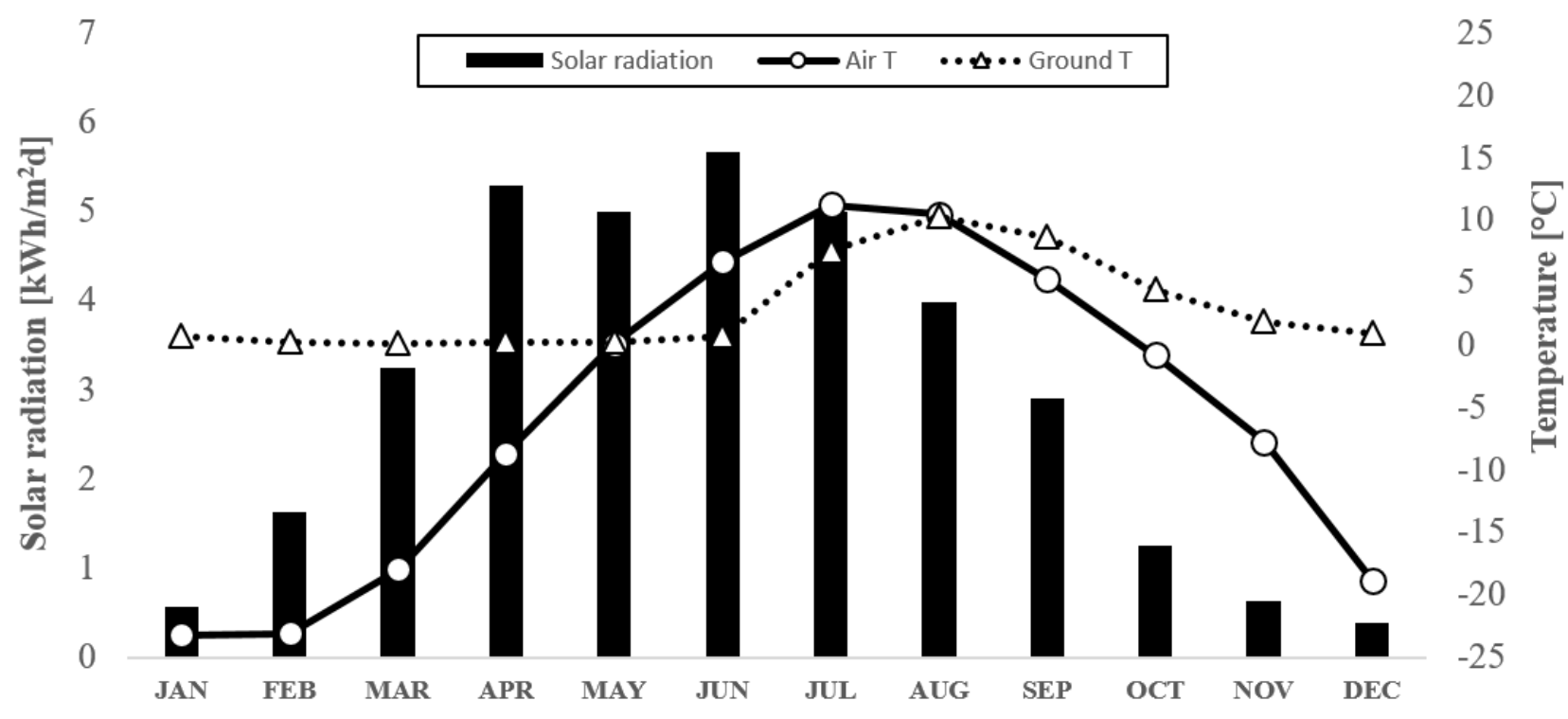

Figure 2 - Monthly solar radiation, mean air temperature [47] and mean ground temperature (0.25 m b.g.l.) in Kuujjuaq.

The study area is located in the western part of the Southeastern Churchill Province (SECP), part of the Canadian Shield ([66,67] and references therein). The main lithological units present in Kuujjuaq and the surroundings are diorites and gabbros from Complexe de Kaslac $(1.8 \mathrm{Ga})$, tonalitic gneisses of Pluton de Kuujjuaq (1.8 Ga) and granoblastic paragneisses of the Suite de la Baleine (Archean to Paleoproterozoic; [67]). The unconsolidated Quaternary deposits mainly consist of littoral and pre-littoral sediments alternating with intertidal deposits related to different cycles of transgression and regression of the Iberville Sea [60] (see Fig. 1). Glacial till often covers bedrock outcrops and it is common to find till underlying the marine sediments. Coarse-grained alluvial materials are found along small stream valleys.

\section{Methodology}

\subsection{Field surveys and geological conceptual model}

Two field campaigns were carried out in Kuujjuaq in the summers of 2017 and 2018. The work involved sampling rocks and Quaternary sediments, recording temperature logs in available wells, and performing slug tests and electrical resistivity tomography (ERT) surveys. A detailed description of the field work was reported in [68,69]. The two ERT lines carried out at the site of the pumping station [68] showed saturated marine deposits overlying glacial till on top of bedrock, which crops out to the south of the study area (see Fig. 1). No evidence of frozen ground was revealed by the ERT (depth of investigation $20 \mathrm{~m}$ ), even though the groundwater temperature was around $1^{\circ} \mathrm{C}$. The proximity of the lake in a possible talik setting, the coarsegrained sands and the significant groundwater advection collectively prevent freezing in this unit and the development of permafrost at this locality.

To estimate the hydraulic conductivity of the marine deposits, a dozen tests based on the Porchet method [70] were carried out in manually drilled boreholes in the study area. An average hydraulic conductivity of 
$5 \times 10^{-5} \mathrm{~m} \mathrm{~s}^{-1}$ was assessed. Static groundwater level was also measured in 7 of the boreholes using a GPS antenna (values of $25-30 \mathrm{~cm}$ b.g.l.), along with the lake water level at 6 points along the coast (Fig. 3). These values were then interpolated through the inverse distance weighted algorithm in QGIS [71] to infer the local hydraulic gradient and groundwater flow direction. The reference hydrogeological conceptual model is thus characterized by a flow directed towards the lake with a mean hydraulic gradient of $1.5 \%$, a Darcy velocity of $7 \mathrm{~cm} \mathrm{~d}^{-1}$ and a porosity estimated to be 0.35 based on geological observation and available literature [72].

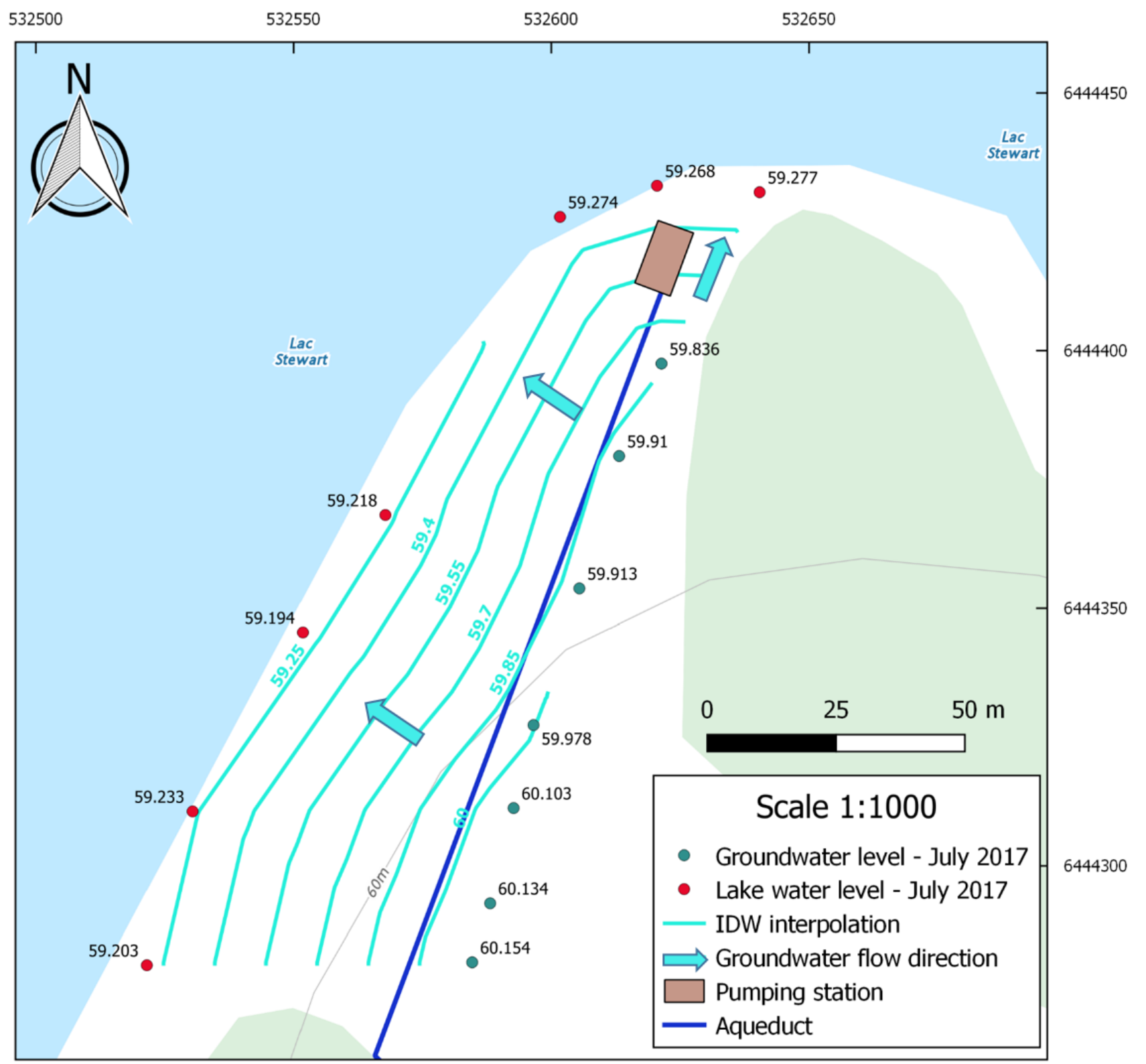

Figure 3 - Local conditions of groundwater flow in the study area (values are in $m$ a.s.l.; coordinates in NAD83/UTM Zone 19N).

The thermal properties of the Quaternary sediments were investigated with a KD2 Pro Thermal Properties Analyzer [73]. The saturated marine deposits have an average thermal conductivity $(\lambda)$ of $1.54 \pm$ $0.19 \mathrm{~W} \mathrm{~m}^{-1} \mathrm{~K}^{-1}$ and a heat capacity $(C v)$ of $3.03 \pm 0.21 \mathrm{MJ} \mathrm{m}^{-3} \mathrm{~K}^{-1}(8$ samples analysed, 5 measurements on each sample) [68]; these values were used for the simulations described in the following sections. 
Based on the results of the field campaign and laboratory analyses, the geological conceptual model is assumed to be characterized by alluvial sediments free of frozen water and homogeneous from both thermal and hydrogeological points of view. BHE are hosted in the unconsolidated sediments without interacting with underlying bedrock, and groundwater flow is constant in direction and magnitude throughout the year.

\subsection{BTES system}

The Stewart Lake pumping station withdraws water from the lake during the cold season at around $3-4{ }^{\circ} \mathrm{C}$ [74] (Fig. 4). Before being pumped in the pipeline, the water is heated to around $7{ }^{\circ} \mathrm{C}$ to prevent freezing during the $4.8 \mathrm{~km}$ route to the village. Currently, the heating system is fed by two diesel boilers with a nominal capacity of $100 \mathrm{~kW}$. Lemieux et al. [61] reported a water consumption of $108 \mathrm{ld}^{-1}$ per person in Umiujaq, a smaller Nunavik village. The Québec Ministry of Environment defined minimum values of $200-2501 \mathrm{~d}^{-1}$ [15]. According to these data, a value of $200 \mathrm{ld}^{-1}$ was chosen for the village and an average pumping rate of $20 \mathrm{~m}^{3} \mathrm{~h}^{-1}$ was fixed throughout the season. An energy demand of around $400 \mathrm{MWh}$ is estimated from October to March, with maximum need (76 MWh) and peak heating load (106 kW) occurring in November (Fig. 4). The system is designed to operate in charge mode from April to September in order to exploit the secondhighest solar radiation available in April $\left(5.3 \mathrm{kWh} \mathrm{m}^{-2} \mathrm{~d}^{-1}\right)$. The aim is to use the BTES to cover $50 \%$ of the demand from October to March (200 MWh) and an auxiliary diesel boiler of $80 \mathrm{~kW}$ to cover the remaining $200 \mathrm{MWh}$ together with the heating needs from April to June (170 MWh). Following [63], the base case scenario (SC1) has a gross solar collector area of $1000 \mathrm{~m}^{2}$, an underground long-term storage of $22000 \mathrm{~m}^{3}$ and a short-term tank of $100 \mathrm{~m}^{3}$.

\section{0}

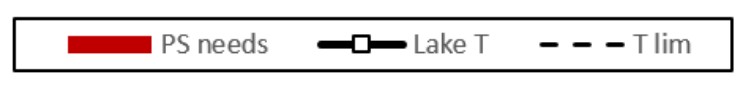

80

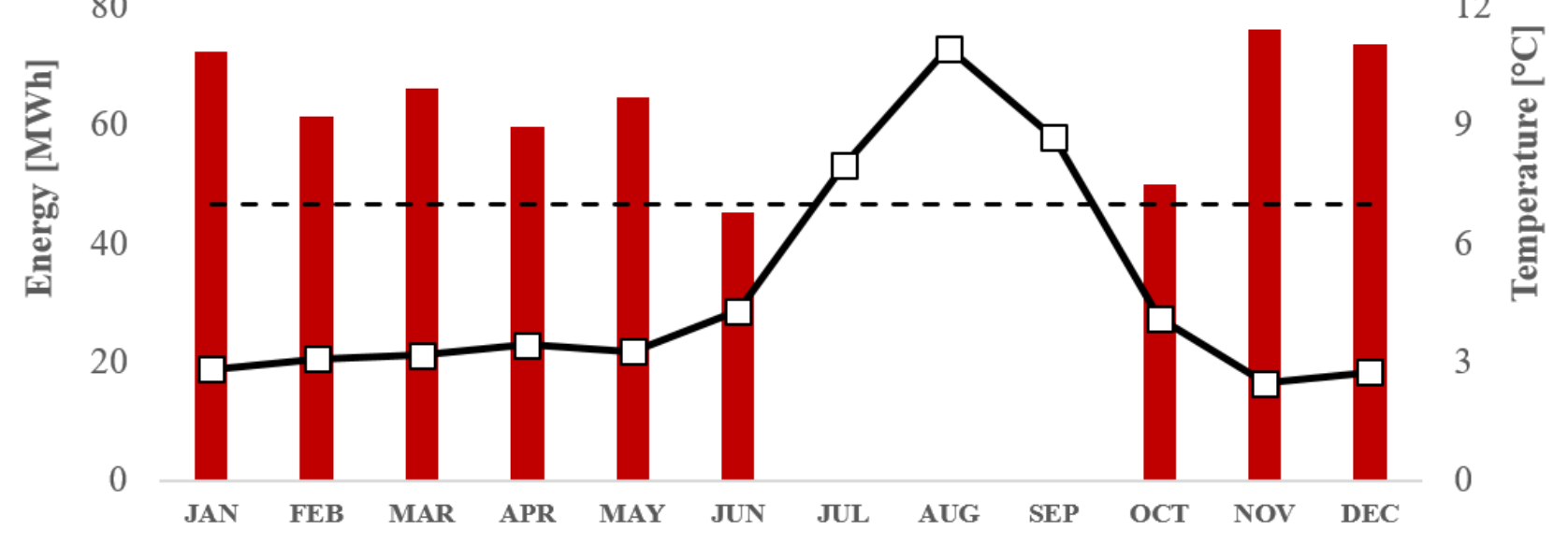

Figure 4 - Monthly energy needs of the pumping station (PS) to reach a water temperature limit (T lim) of $7{ }^{\circ} \mathrm{C}$. The temperature at the bottom of Stewart Lake is also shown (average of the 2004-2005 and 2009-2010 seasons; [74]).

Ground storage is highly dependent on the thermal and hydraulic properties of the subsurface. The reference ground storage was designed with a hundred single U-pipe BHEs to a depth of $30 \mathrm{~m}$, divided into five series 
of 20 boreholes hydraulically connected in parallel, in a circular arrangement with $3 \mathrm{~m}$ spacing (ca. $22000 \mathrm{~m}^{3}$, radius $15 \mathrm{~m}$, shape factor equal to 1 ). This concept design was mainly driven by the fact that BTES systems are better at limiting heat loss when the shape factor is closer to 1 , and thus the surface-to-volume ratio is minimized $[21,42,45,46,75]$. The study site is of particular interest due to the presence of saturated sands with no permafrost, which shows much higher heat capacity than the underlying bedrock (see Section 3.1). The solar and BTES loops are coupled through a cylindrical short-term storage tank (STST) and the heat carrier fluid consists of a mixture of water and $50 \%$ vol. propylene glycol (minimal working temperature of $-30{ }^{\circ} \mathrm{C}$ ) to prevent freezing. The water withdrawn from Stewart Lake circulates within the STST through a coiled immersed heat exchanger (HX), as proposed by [38], to be heated in winter.

During the charge phase, the solar collectors produce energy that is sent to the BTES via the STST. The BHEs then distribute heat from the centre to the outer zones of the storage volume. In winter, the thermal energy is discharged from the BTES, with the fluid flowing from the borders to the centre in order to limit cooling, and transferred to the ST tank. The solar loop is allowed to work even during the discharge phase if solar production is enough to help the underground storage heat the STST.

\subsection{TRNSYS model}

TRNSYS is a commercial simulation modular environment allowing transient modelling of complex energy systems [62]. Several different components (Types) are individually solved by single systems of equations and then coupled together to achieve the final outputs required by the user. The code has been widely adopted to simulate underground thermal energy storage systems in the last 20 years $[29,36,38,76-78]$. The underground is simulated with the duct storage (DST) model developed by [79]. The DST is a cylindrical shaped storage volume with a vertical symmetry axis, where the BHEs are assumed to be uniformly distributed depending on the required volume size and spacing. Convective heat transfer in the ducts and conductive heat transfer in the ground are simulated together to output the ground temperature, where three different problems are solved numerically with the finite difference method (global and local temperatures) and analytically (steady state problem). The total temperature is determined by superposing the three different parts in order to ensure a fast and accurate simulation tool [79]. 


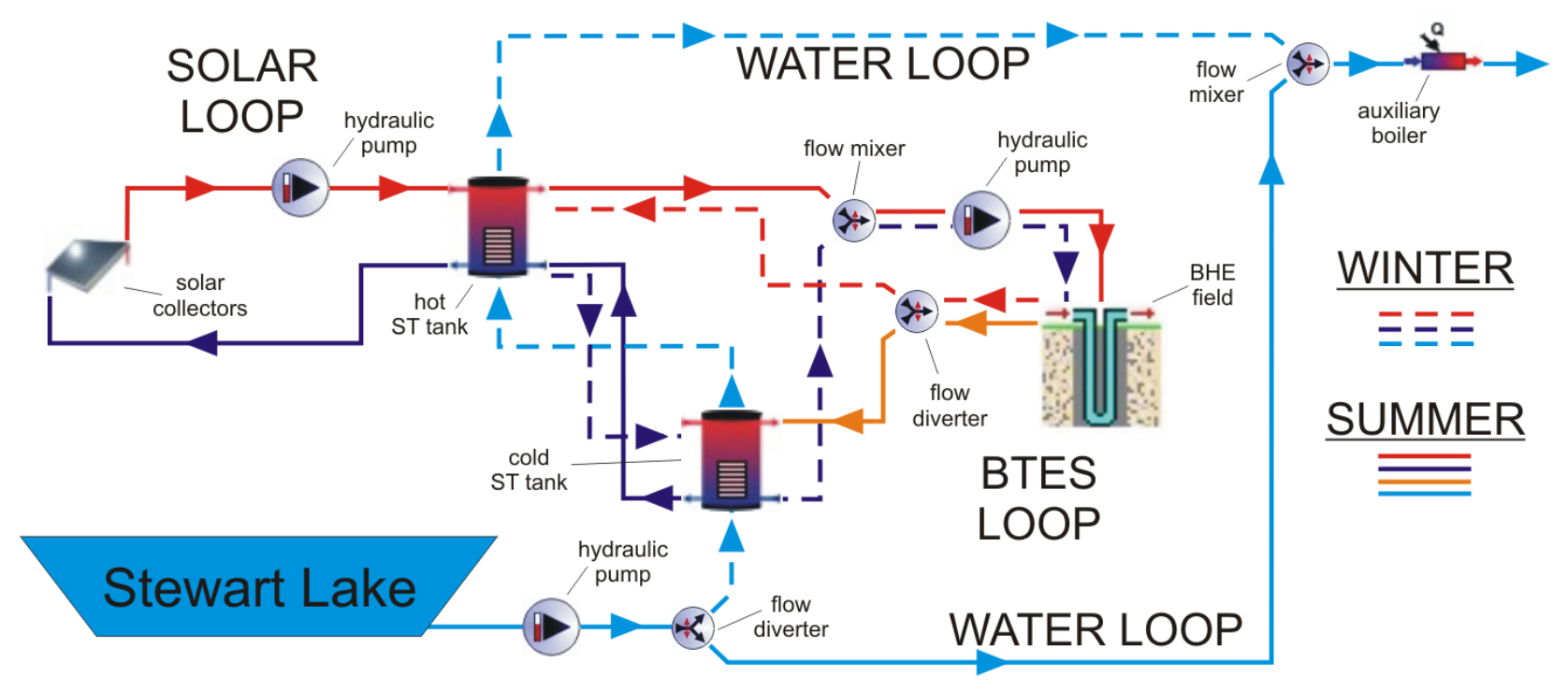

Figure 5 - Diagram of the BTES system as designed in scenario SC2. Other scenarios differ slightly as reported in Tab. 3.

The system (Fig. 5) was built in TRNSYS 18 with the following Types:

- Type $557 a$ is the currently available type to simulate the ground storage through the DST model [79]. 10 radial regions and 10 vertical regions were adopted to model the underground temperature. A top insulation layer of $1 \mathrm{~m}$ in thickness was simulated with a thermal conductivity of $0.1 \mathrm{~W} \mathrm{~m}^{-1} \mathrm{~K}^{-1}$, an average between very low conductive but expensive synthetic materials $[29,76,80]$ and cheaper natural sands [81] or waste products [30,82]. All other parameters are reported in Tab. 1;

- Type534 was chosen to simulate the STST, a vertical cylindrical storage tank with immersed HX that gives the needed flexibility on the number of inlets/outlets (up to 10), the number and type of immersed HX (up to 5) and the number of nodes (up to 20) to increase the model complexity and improve stratification. A 5-m high tank with a volume of $100 \mathrm{~m}^{3}$ was chosen, 2 inlets/outlets were selected to connect the solar and BTES loops, a coiled HX $\left(\mathrm{d}_{\mathrm{i}}=50 \mathrm{~cm}, \lambda_{\mathrm{HX}}=400 \mathrm{~W} \mathrm{~m}^{-1} \mathrm{~K}^{-1}\right.$, i.e. copper, [38] $)$ hosts the water distribution loop, and 20 nodes provide high accuracy to the simulation;

- Typelb was chosen for the solar panels. It simulates a flat-plate solar collector with quadratic efficiency, $\mathrm{a}_{0}=0.8, \mathrm{a}_{1}=13 \mathrm{~kJ} \mathrm{~h}^{-1} \mathrm{~m}^{-2} \mathrm{~K}^{-1}$ and $\mathrm{a}_{2}=0.05 \mathrm{~kJ} \mathrm{~h}^{-1} \mathrm{~m}^{-2} \mathrm{~K}^{-2}$. The total collector area is $1000 \mathrm{~m}^{2}$, divided into 250 series of 4 collectors and a specific flow rate of around $40 \mathrm{l} \mathrm{s}^{-1} \mathrm{~m}^{-2}$; the maintenance of the solar collectors' surface is assumed to be not affected by snow cover during the charge phase (snow can sometimes fall in April and May);

- Type6 was selected to simulate the auxiliary diesel boiler with a maximum heating power of $80 \mathrm{~kW}$ and a target outlet temperature of $7^{\circ} \mathrm{C}$;

- Type110 is a variable speed pump adopted to run the solar, BTES and water loops; constant total flow rates of 15,40 and $20 \mathrm{~m}^{-3} \mathrm{~h}^{-1}$ and powers of $0.2,3.3$ and $0.3 \mathrm{~kW}$ were adopted, respectively;

- Type11d and Typellf are mixing and diverting valves used to mix or separate flows along the circuit when necessary; 
- Type $2 b$ and Type14h are an on/off differential controller and a time-dependent forcing function adopted to control the flows depending on selected criteria and to discriminate between the charge and discharge phases of the system;

- Typical meteorological year (Type15) from the Kuujjuaq airport weather station was selected to provide crucial input data to the solar panels and the storage volume. The lake temperature series reported in Fig. 3 (assumed to be monthly constant for simplicity) was assigned to the water loop entering the system.

The features described above belong to the base case scenario (SC1) that was built to simulate the dynamic behaviour of the system during a 5-year simulation, alternating charge and discharge phases (Tab. 2). Another 10 scenarios were created to optimize the system, mainly focussing on the characteristics of the BTES volume and related elements (Tab. 3). In SC2, a second ST tank was added to improve stratification and reduce the BTES inlet temperature. SC3 has a higher storage shape factor (1.5 vs. 1.0). In SC4, the second tank was used during the discharge phase only, and in SC5 a 1-year pre-heating period was tested to raise the temperature by $10{ }^{\circ} \mathrm{C}$. In SC6 and SC7, the number of BHEs was halved to evaluate possible savings in drilling, whereas in SC8 and SC9, the solar area was increased by $50 \%$. The last two scenarios were meant to test a lower amount of glycol in the heat carrier fluid (SC10) and a higher flow rate in the BTES loop (SC11) in order to increase the Reynolds number ( $R e$ ) and improve the heat exchange between the BHE and the surrounding ground [83].

Table 1 - Main parameters of the BHE storage.

\begin{tabular}{cc} 
Parameter & Value \\
\hline BHE type & $1-\mathrm{U}$ \\
Number of BHE $(-)$ & 100 \\
Number of BHE in series $(-)$ & 5 \\
BHE depth $(\mathrm{m})$ & 30 \\
$d_{\mathrm{BHE}}(\mathrm{mm})$ & 152.4 \\
$d_{o}(\mathrm{~mm})$ & 32 \\
Top insulation thickness $(\mathrm{m})$ & 1 \\
$\lambda$ ground $\left(\mathrm{W} \mathrm{m} \mathrm{K}^{-1} \mathrm{~K}^{-1}\right)$ & 1.5 \\
$\lambda$ grout $\left(\mathrm{W} \mathrm{m} \mathrm{K}^{-1}\right)$ & 1.5 \\
$\lambda$ pipe $\left(\mathrm{W} \mathrm{m} \mathrm{K}^{-1}\right)$ & 0.4 \\
$\lambda$ insulation $\left(\mathrm{W} \mathrm{m}^{-1} \mathrm{~K}^{-1}\right)$ & 0.1 \\
$C v$ ground $\left(\mathrm{MJ} \mathrm{m}^{-3} \mathrm{~K}^{-1}\right)$ & 3.0 \\
$C v$ grout $\left(\mathrm{MJ} \mathrm{m}^{-3} \mathrm{~K}^{-1}\right)$ & 3.9 \\
$C v$ pipe $\left(\mathrm{MJ} \mathrm{m}^{-3} \mathrm{~K}^{-1}\right)$ & 1.5 \\
\hline
\end{tabular}

Table 2 - Charge and discharge cycles in hours during the 5-year simulation. For simplicity, the system works in charge mode even from January to March of year 1.

\begin{tabular}{|c|c|c|c|c|c|c|}
\hline & Year 1 & Year 2 & Year 3 & Year 4 & Year 5 & \\
\hline JAN & 744 & 9504 & 18264 & 27024 & 35784 & 빙 \\
\hline FEB & 1416 & 10176 & 18936 & 27696 & 36456 & $\underset{I}{\mathbb{I}}$ \\
\hline MAR & 2160 & 10920 & 19680 & 28440 & 37200 & $\bar{a}$ \\
\hline APR & 2880 & 11640 & 20400 & 29160 & 37920 & $\begin{array}{ll}\mathbb{I} \\
\text { I }\end{array}$ \\
\hline
\end{tabular}




\begin{tabular}{|c|c|c|c|c|c|c|}
\hline MAY & 3624 & 12384 & 21144 & 29904 & 38664 & \\
\hline JUN & 4344 & 13104 & 21864 & 30624 & 39384 & \\
\hline JUL & 5088 & 13848 & 22608 & 31368 & 40128 & \\
\hline AGO & 5832 & 14592 & 23352 & 32112 & 40872 & \\
\hline SET & 6552 & 15312 & 24072 & 32832 & 41592 & \\
\hline OCT & 7296 & 16056 & 24816 & 33576 & 42336 & 떵 \\
\hline NOV & 8016 & 16776 & 25536 & 34296 & 43056 & 至 \\
\hline DEC & 8760 & 17520 & 26280 & 35040 & 43800 & 2 \\
\hline
\end{tabular}

Table 3 - Characteristics of the scenarios simulated in TRNSYS (STST - short term storage tank, CHR - charge phase, DIS - discharge phase, HCF - heat carrier fluid). Shape factor is calculated as the depth-to-diameter ratio.

$$
\text { (Last page) }
$$

\subsection{FEFLOW model}

The DST module does not take into account subsurface heat transfer by advection [79], but groundwater flow is expected to play a significant role in the overall amount of heat loss at the study site. For this reason, a detailed underground model was developed in FEFLOW, a commercial finite element numerical code able to couple heat, flow and mass transport in porous media [64]. The BHEs are modelled as 1D elements with equivalent thermal resistances fully incorporated in 3D triangular prismatic element meshes. The heat governing equations are iteratively solved according to the analytical solution of [84] or the numerical approach proposed by $[85,86]$. To speed up the calculation, the model described here used the analytical technique that assumes local steady state conditions and immediate thermal equilibrium between inlet and outlet pipes. It was demonstrated that this approach closely matches the numerical strategy when the heat load is constant for times longer than 2-3 h [59], a condition that was followed to comply with the limitation of the solution. A dynamic coupling between TRNSYS and FEFLOW was first developed and tested at the Crailsheim BTES site [57,59], but the Type331 and FEFLOW's IFM module are no longer available. The first $10920 \mathrm{~h}$ of TRNSYS simulations were replicated in FEFLOW by charging the system for $6552 \mathrm{~h}$ (from January to September of year 1) and discharging it for the remaining $4368 \mathrm{~h}$ (until March of year 2) to deal with the lack of an updated coupling option between the two codes. Even if no direct coupling was possible, this methodology made it possible to approximate the system's interaction with the local groundwater flow.

A 3D model $100 \times 100 \times 50 \mathrm{~m}$ was built and spatially discretized with a mesh of around 500000 triangular prismatic elements, refined near the BHEs and progressively coarser towards the model boundary. Grid independence validation was carried out to select the mesh element number as the best trade-off between computation time and stability of the results. The refinement around the BHEs consisted of 6 nodes according 
to the methodology described by [59] to produce an optimal nodal distance of $0.45 \mathrm{~m}$ and thus ensure numerical stability and accuracy. The automatic time-step control scheme was adopted for the time discretization to allow the solver to choose the appropriate length depending on the change of the primary variables; around 50000 and 15000 time steps were needed to run the charge and discharge simulations, respectively. The geological and hydrogeological characteristics of the underground are those reported in the previous sections and the features of the BHE field listed in Tab. 1. A temperature initial condition (IC) of $0{ }^{\circ} \mathrm{C}$ was set to the whole model and the specific BHE tool was adopted to solve the heat transport equation, where temperature is subject to a set of Dirichlet, Neumann and Cauchy type boundary conditions (BC) [64]. Dirichlet BC at the top (mean air temperature) and Neumann BC at the bottom (geothermal heat flux) of the model were not assigned in order to speed up the calculation. Zarrella and Pasquier [55] and Nguyen et al. [56] stressed the fact that air ambient temperature cannot be neglected in the simulation of both GSHP and BTES technologies. However, they highlighted that this is particularly true for significant temperature differences between atmosphere and subsurface, and [56] pointed out that groundwater has a much more important effect than this element. Underground temperature was recorded in Kuujjuaq at $20 \mathrm{~cm}$ b.g.l. (see Fig. 2) and from October to March (charge period) was on average $0.40{ }^{\circ} \mathrm{C}$ with a standard deviation of 1.28 , showing that snow cover plays an important insulation role; the first assumption is therefore acceptable. In addition, given the insignificant amount of energy provided annually by the geothermal heat flux (in the order of $0.3 \mathrm{MWh}^{-1}$ for SC1) and the short simulation time, the second assumption has also negligible influence on the results. The groundwater flow IC and BC were assigned in order to get a $1.5 \%$ constant hydraulic gradient within the underground store. Solid-liquid phase changes were not included in the simulation since the underground temperature remains higher than $1{ }^{\circ} \mathrm{C}$ after a few hundred hours from the beginning. Therefore, no freeze-thaw cycles were expected to occur within the ground throughout the simulation time [87].

The aim of the FEFLOW simulation was to test different geometrical dispositions and BHE connections in order to evaluate the different temperature distributions within the ground and the additional heat loss generated by groundwater advection. In this regard, four scenarios were simulated using SC2 as a reference (Tab. 4): two scenarios have a conventional circular disposition, one with the same characteristics as SC2 (SC2_A) and the other with wider spacing (SC2_B); the other two scenarios have a square arrangement as in [34], with centre-to-border (SC2_C) and alternate (SC2_D) BHE links (Fig. 6). Scenario D, a new connection design, is proposed for generating the warm core at the upstream end of the storage in order to limit the influence of groundwater flow and allow the system to better retrieve energy in wintertime. The BTES charging ( 0 to $6552 \mathrm{~h}$ ) and discharging ( 6553 to $10920 \mathrm{~h}$ ) loads modelled by TRNSYS in SC2 were assigned as BC to the boreholes, similarly connected in 20 series of five BHEs. Accordingly, the circulation was switched from centre-to-border (charge) to border-to-centre (discharge) in $\mathrm{SC} 2 \mathrm{~A} / \mathrm{B} / \mathrm{C}$, and from downward (charge) to upward (discharge) with respect to groundwater flow in SC2_D.

Table 4 - Characteristics of the scenarios simulated in FEFLOW (C - centre, B - border). 


\begin{tabular}{|c|c|c|c|c|}
\hline Spacing [m] & 2.9 & 3.8 & 2.9 & 2.9 \\
\hline Storage shape on surface [-] & circle & circle & square & square \\
\hline Radius / Half side [m] & 15 & 20 & 15 & 15 \\
\hline Shape factor [-] & 0.99 & 0.75 & 0.99 & 0.99 \\
\hline Storage volume $\left[\mathrm{m}^{3}\right]$ & 22000 & 38000 & 22000 & 22000 \\
\hline BHE connection in CHR & $\mathrm{C}$ to $\mathrm{B}$ & $\mathrm{C}$ to $\mathrm{B}$ & $\mathrm{C}$ to $\mathrm{B}$ & downward \\
\hline BHE connection in CHR & B to $\mathrm{C}$ & $\mathrm{B}$ to $\mathrm{C}$ & $\mathrm{B}$ to $\mathrm{C}$ & upward \\
\hline
\end{tabular}

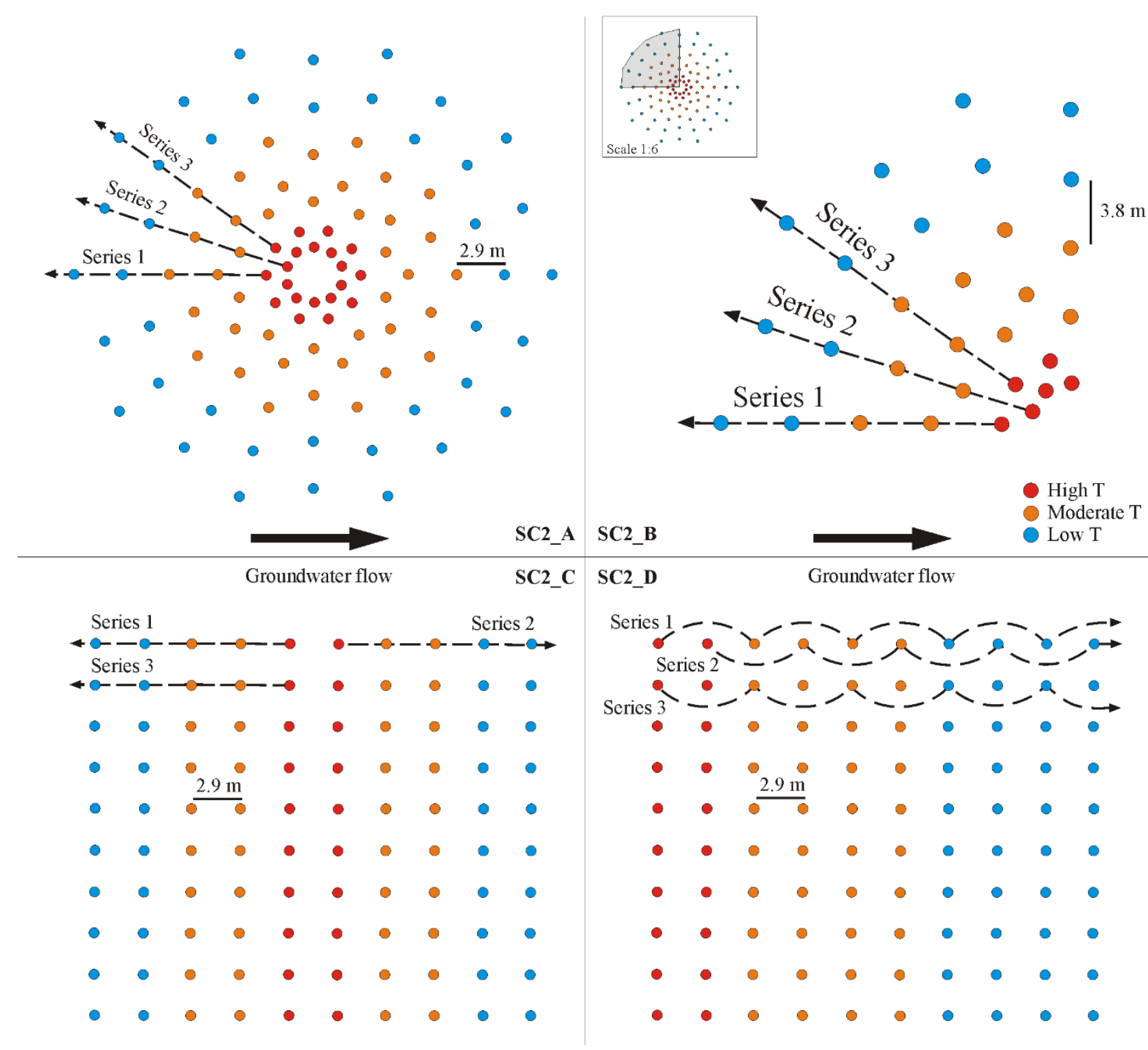

Figure 6 - Borehole dispositions in the four FEFLOW scenarios. Flow directions refer to the charge phase; the discharge occurs in reverse mode. Red, orange and blue indicate the expected stratification in the storage volume.

\subsection{Life-cycle cost analysis}

In order to evaluate the economic benefits of BTES in the subarctic climate of Kuujjuaq, a 50-years life-cycle cost analysis (LCCA) was carried out in comparison to the business as usual (BAU) scenario, which is the current diesel-dependent situation with cost of diesel. In Nunavik, drilling is an expensive activity and expertise 
in borehole heat exchangers installation is lacking. Therefore, two scenarios with optimistic (37 USD $\mathrm{m}^{-1}$, BTES 37) and realistic (224 USD m ${ }^{-1}$, BTES 224) costs for BHE drilling and installation were analysed. Moreover, two additional financial scenarios were considered: the government contributes with an incentive program paying the $50 \%$ of the solar panels and the BHE, and the cost of electricity and diesel are subsidised with current rates (see Section 1). Finally, a last scenario where the electricity necessary to run the BTES is produced by solar photovoltaic (PV) panels rather than the diesel power plant is also analysed.

The total cost $\left(C_{t}\right)$ was divided into capital cost $\left(C_{c}\right)$, annual cost $\left(C_{a}\right)$, and periodic $\operatorname{cost}\left(C_{p}\right.$; Eq. 1). Capital cost included the cost of equipment, installation or labour and shipping. Annual cost enclosed the costs of energy (diesel and electricity), maintenance and GHG emissions. Periodic cost included the cost of equipment to be replaced at the end of its lifetime, installation and shipping.

$$
C_{\mathrm{t}}=C_{\mathrm{c}}+C_{\mathrm{a}}+C_{\mathrm{p}}
$$

GHG emissions were calculated considering 2.64 tonnes eq. $\mathrm{CO}_{2} \mathrm{l}^{-1}$ for diesel. Emissions for each scenario were multiplied by 14.48 USD t ${ }^{-1}$, the estimated price of carbon in Québec's carbon market in 2020, to obtain the cost of GHG emissions associated with each heating option.

The net present cost (NPC) and levelized cost of energy (LCOE) were chosen to compare the 50-years lifecycle costs (LCCs) of the five alternatives. The NPC formula converts or discounts costs incurred at different time point $n$ during the project life-cycle, at the discount rate $r$ to a common point in time, which in this study is 2020 . NPC is given by:

$$
N P C=\sum_{n=0}^{N} \frac{C_{\mathrm{t}, \mathrm{n}}}{(1+r)^{\mathrm{n}}}
$$

The LCOE is an additional way to rank alternative projects. Compared to the NPC method, LCOE considers both the total LCC and the total amount of energy produced, both of which are discounted over the project's lifetime. It indicates the minimum cost per unit of energy that will recover the lifetime costs of the system and is measured by dividing the NPC of the heating system by its total lifetime energy output, i.e. the 50-year accumulated annual energy output $E_{t}$ of each heating scenario. LCOE is calculated as follows:

$$
L C O E=\frac{N P C}{\sum_{n=1}^{N} \frac{E_{\mathrm{t}, \mathrm{n}}}{(1+r)^{\mathrm{n}}}}
$$

More details about the LCCA and related assumptions are reported in Appendix A.

\section{Results}

\subsection{TRNSYS}

\subsubsection{Underground energy balance}

The results of the simulation show that subsurface temperature rises to $20-30{ }^{\circ} \mathrm{C}$ at the end of the charge phase and then returns to $5-12{ }^{\circ} \mathrm{C}$ after the discharge occurred (Fig. 7). An increase from year 1 to 5 is 
generally observed in all the scenarios, but equilibrium between heat injection and extraction is reached by year 3. Year 3 was therefore chosen as a reference point to compare all the scenarios (Tab. 5). Two HR indicators were calculated as follows:

$$
\begin{gathered}
\eta_{B T E S 1}=\frac{E_{E X T}}{E_{I N J}} \\
\eta_{B T E S 2}=\frac{E_{E X T}}{E_{S T O}}=\frac{E_{E X T}}{E_{I N J}-E_{L O S}}
\end{gathered}
$$

where $E_{\mathrm{EXT}}, E_{\mathrm{INJ}}, E_{\mathrm{STO}}$ and $E_{\mathrm{LOS}}(\mathrm{J})$ refer to the energy extracted during discharge, and injected, stored and lost during charge by the underground, respectively. While $\eta_{\mathrm{BTES}}$ is the conventional way to indicate BTES heat recovery (e.g. $[29,36,82,88]), \eta_{\mathrm{BTES} 2}$ gives an idea of the influence of the heat loss on the overall operation of the system.

SC2 extracts more energy (13\% in year 3) than SC1 due to the second short-term tank added to the system. This is also highlighted by the underground temperature at the end of the discharge, systematically $2-3{ }^{\circ} \mathrm{C}$ lower than in SC1 (Fig. 7). SC3 reaches higher temperature in the storage (more than $25^{\circ} \mathrm{C}$ already in the first year) and easily extracts energy during the discharge ( $\eta_{\mathrm{BTES}}=95 \%$; Tab. 5), showing $6-7{ }^{\circ} \mathrm{C}$ as the minimum temperature at the centre. This is due to a smaller underground volume (less than half that of SC1 and SC2), which also allows the system to easily reach the equilibrium. Nevertheless, with respect to the previous scenarios, the results for solar production (-17\%), energy injection (-19\%), storage (-26\%) and heat loss $(+5$ to $+6 \%)$ make this scenario under-designed for the chosen gross solar area. SC4 is slightly better than SC2 in all the elements presented in Tab. 5, showing that using only the cold STST to discharge the system does not provide significantly better ability to retrieve energy from the subsurface (534 GJ against 527 GJ over year 3). At a first glance, SC5 is similar to SC2 and SC4, with comparable solar production (-2 to $-3 \%)$, injection $(-2$ to $-3 \%)$ and $\mathrm{SF}(+2 \%)$. Interestingly, heat losses are smaller in absolute values, with $235 \mathrm{GJ}$ against $246 \mathrm{GJ}$ (SC2) and $252 \mathrm{GJ}$ (SC4), and thus HR is significantly better, with $\eta_{\mathrm{BTES} 1}=61.2 \%$ and $\eta_{\mathrm{BTES} 1}=82.3 \%$, respectively. Moreover, equilibrium is reached in the first year and the system's activity remains stable throughout the simulation, and presumably in the years to come. 

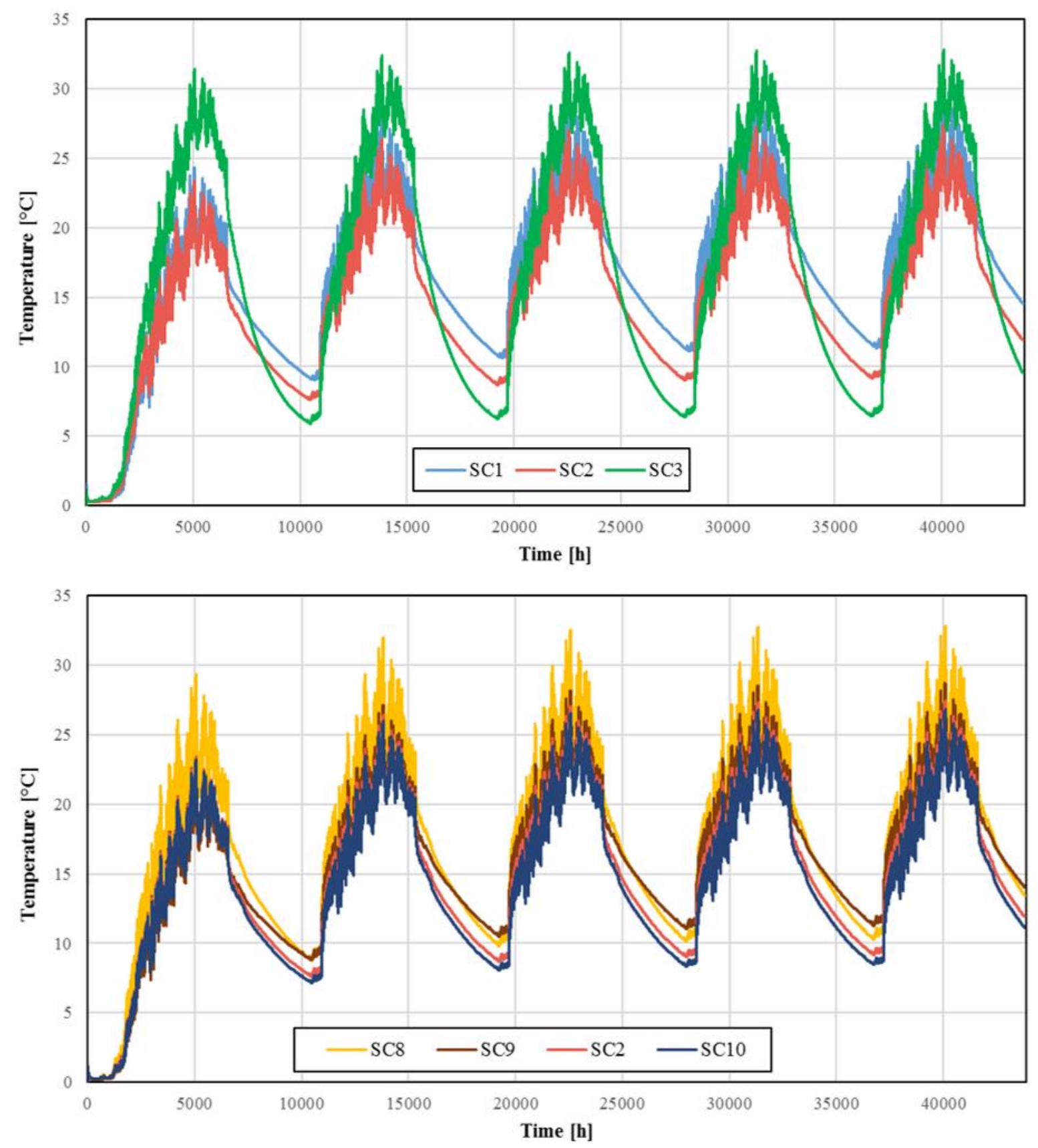

Figure 7 - Subsurface temperature in the centre of the storage of the most interesting scenarios over 5 years.

Table 5 - Summary of the TRNSYS simulations during year 3 (from 19680 to $28440 \mathrm{~h}$ ).

(Last page)

SC6 and SC7 clearly show lower solar production $\left(\eta_{\text {SOLAR }}=21-24 \%\right)$ and hence lower injection and storage. They only retrieve 342 GJ (SC6) and 315 GJ (SC7), providing less than one third of the total energy demand of the pumping station, with solar fractions less than $30 \%$ over the 5-year simulation in both cases. SC7 retrieves $8 \%$ less energy than SC6 and shows the lowest BTES recovery among all the scenarios because it suffers from the wide BHE spacing $(4.1 \mathrm{~m})$, clearly too much for a subsurface thermal conductivity of $1.5 \mathrm{~W} \mathrm{~m}^{-1} \mathrm{~K}^{-1}$. On the other hand, SC6 showed some of the highest HR values among all the simulations: $57 \%$ and $84 \%$ in $\eta_{\mathrm{BTES} 1}$ and $\eta_{\mathrm{BTES} 2}$, respectively. A bigger gross solar area was conversely tested in SC8 and SC9, 
with 100 and 150 BHEs respectively. Solar efficiency is as low as $24 \%$ in SC8 and $29 \%$ in SC9, meaning that the underground storage is not big enough to reach the highest efficiency achieved by other scenarios. Nevertheless, these are the only two options that achieve the target SF, with SC9 at $56 \%$ at year 3. SC9 also has the best result of all scenarios in terms of heat losses both in the STST (2.3\%) and in the BTES (25.2\%); on the other hand, its HR values are among the worst $\left(9^{\text {th }}\right.$ in $\eta_{\mathrm{BTES} 1}$ and $\left.\eta_{\mathrm{BTES}}\right)$. SC10 is able to extract more energy (+6\%) and provide higher HR and SF than SC2. This is due to the use of a $25 \%$ vol. glycol HCF that guarantees a Reynolds number in the range of turbulent flow $(R e=4400$, see Tab. 3), but evidently the minimal working temperature at $-10{ }^{\circ} \mathrm{C}$ could only work for the part of the system below ground. Finally, SC11 results are similar to SC5 in terms of solar production and heat injection, but with extraction (513 GJ) and solar fraction (41.9\%) even lower than SC2. The increase in the BTES loop flow rate raises $R e$ up to the lower limit of the transition zone, but without any clear improvement in underground storage activity.

SC2 was chosen as the reference scenario and thus adopted for more in-depth analyses and comparisons with FEFLOW (see Section 4.2). Solar energy produced show an overall decrease from year 1 to 5 in all 11 scenarios (Tab. 6), as does solar efficiency due to the increasing subsurface temperature. Accordingly, heat injection and storage decrease approaching year 5, but extraction, HR and thus SF improve to 542 GJ, $59.5 \%$ and $43.2 \%$, respectively. The heating load of the pumping station is mainly covered by the BTES in October, with $50 \mathrm{~kW}$ on average over a total need of $65 \mathrm{~kW}$ (Fig. 8). The auxiliary system takes over in November, mainly because of the minimal temperature observed in Stewart Lake, which raises the heating load to the maximum value of $106 \mathrm{~kW}$. From December to March, even if the lake temperature rises slightly, the BTES is not able to cover more than half the monthly load. This is due to the high heating loads (more than $90 \mathrm{~kW}$ from November to March, against $65 \mathrm{~kW}$ in October) and to the progressive discharge of the system. By the end of the winter, more than $40 \%$ of the total energy demand is provided by the storage system, with around $150 \mathrm{MWh}$ reached at year 4 .

Table 6 - Summary of the SC2 simulation results obtained with TRNSYS from year 1 to 4.

(Last page) 


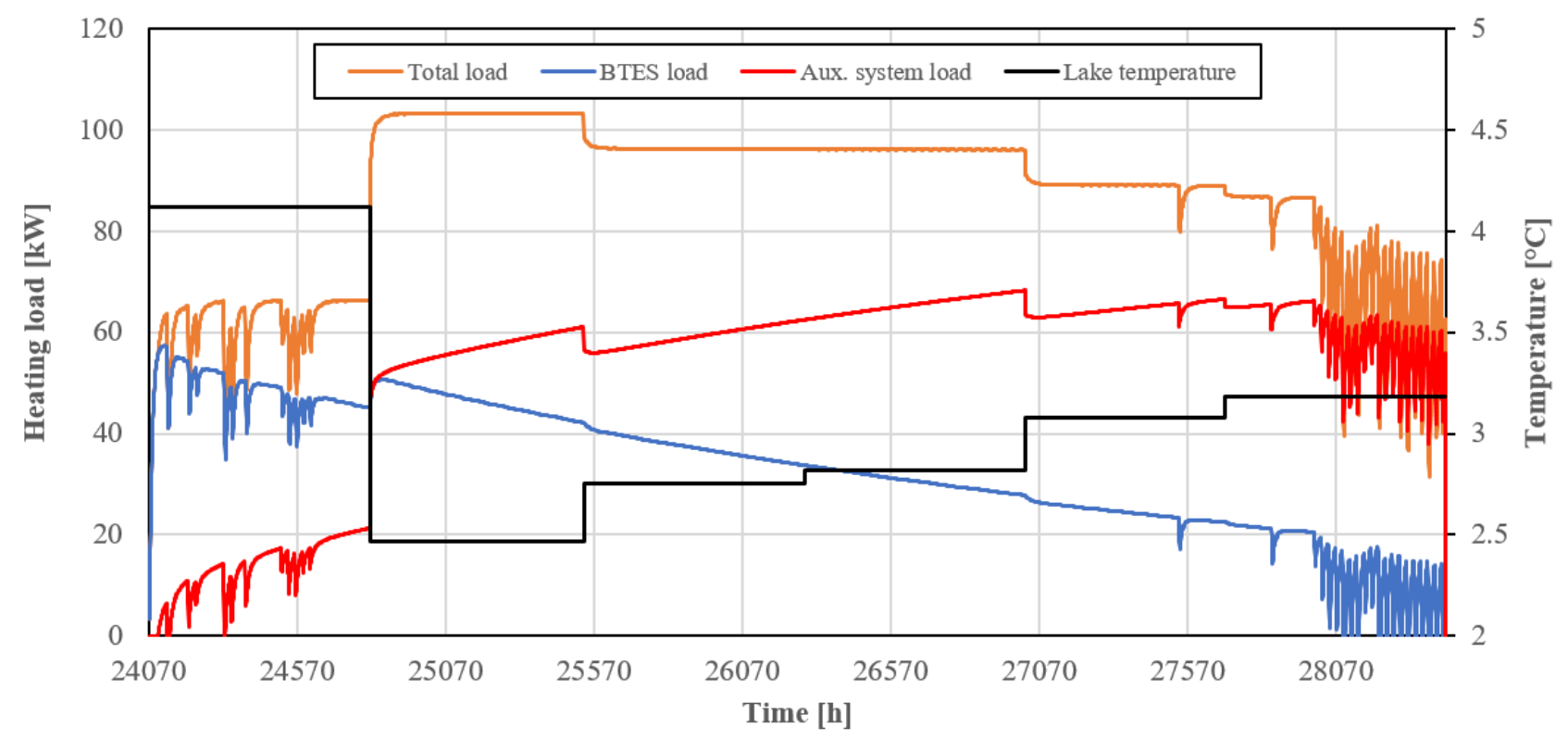

Figure 8 - Heating load of SC2 during the discharge phase in year 3. The orange, blue and red curves represent the total, BTES and auxiliary system loads. The black curve shows the monthly average temperature of the lake.

The load factor was calculated as the ratio between the heating load provided by the BTES and the total heating load. A sharp decreasing trend in load factors is noticed from October to March, but increasing from year 1 to 4 (Fig. 9 and Fig. 11). A minimum of 0.6 (SC1) and maximum of 0.93 (SC3) is reached in October, while the load factor in March can be as low as 0.08 (SC3), but 0.2 on average (Fig. 10). Average load factors throughout the simulation are approximately 0.3 in year 1 and 0.4 in year 4 (Fig. 11). The biggest rises occur in SC1, SC2, SC8 and SC9, whereas SC3 and SC5 are rather stable; the first reaches early equilibrium due to the small subsurface storage volume, while the latter takes advantage of the one-year pre-heating period. SC5, in particular, already shows a mean load factor of 0.4 in year 1, much higher than the load factors of year 4 with SC1, SC2 and SC3, and ties the 0.2 value of SC8 in March (Fig. 10).

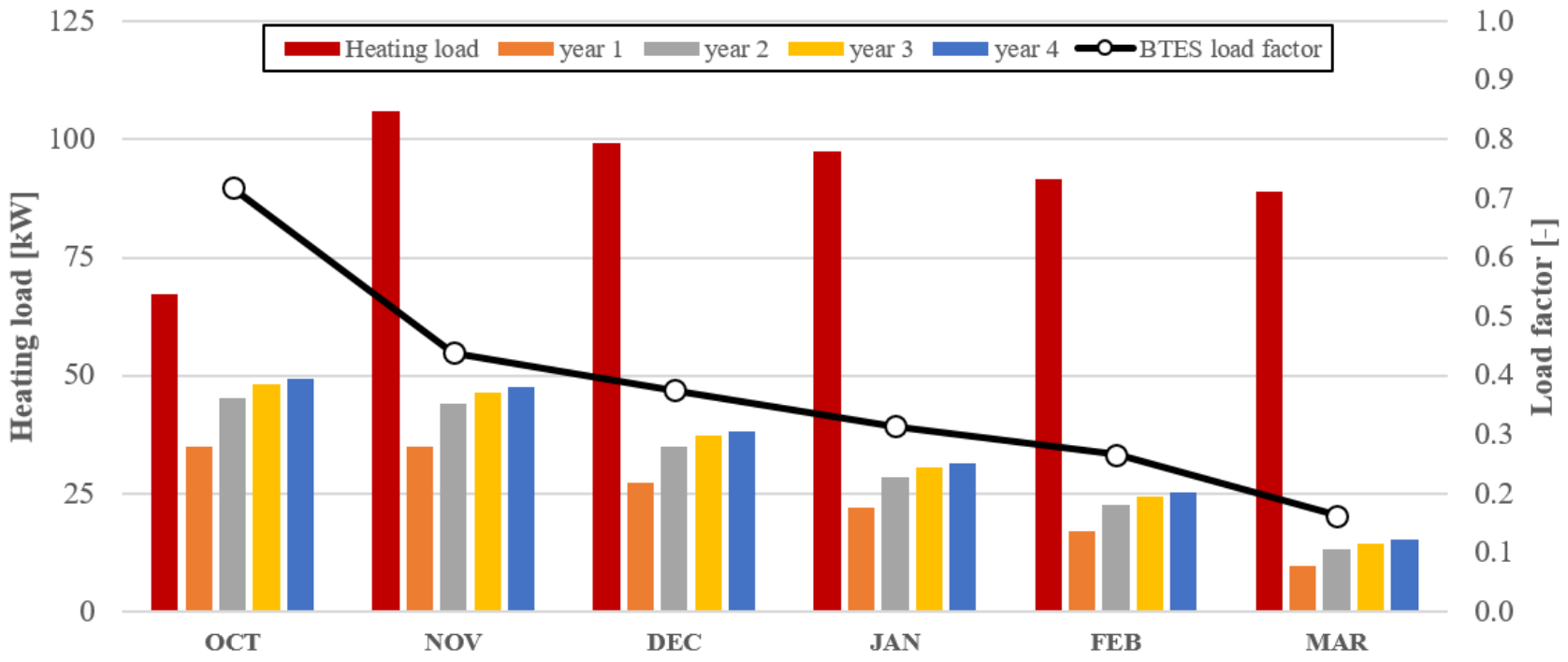

Figure 9 - BTES heating load in SC2 with load factors at year 3. 


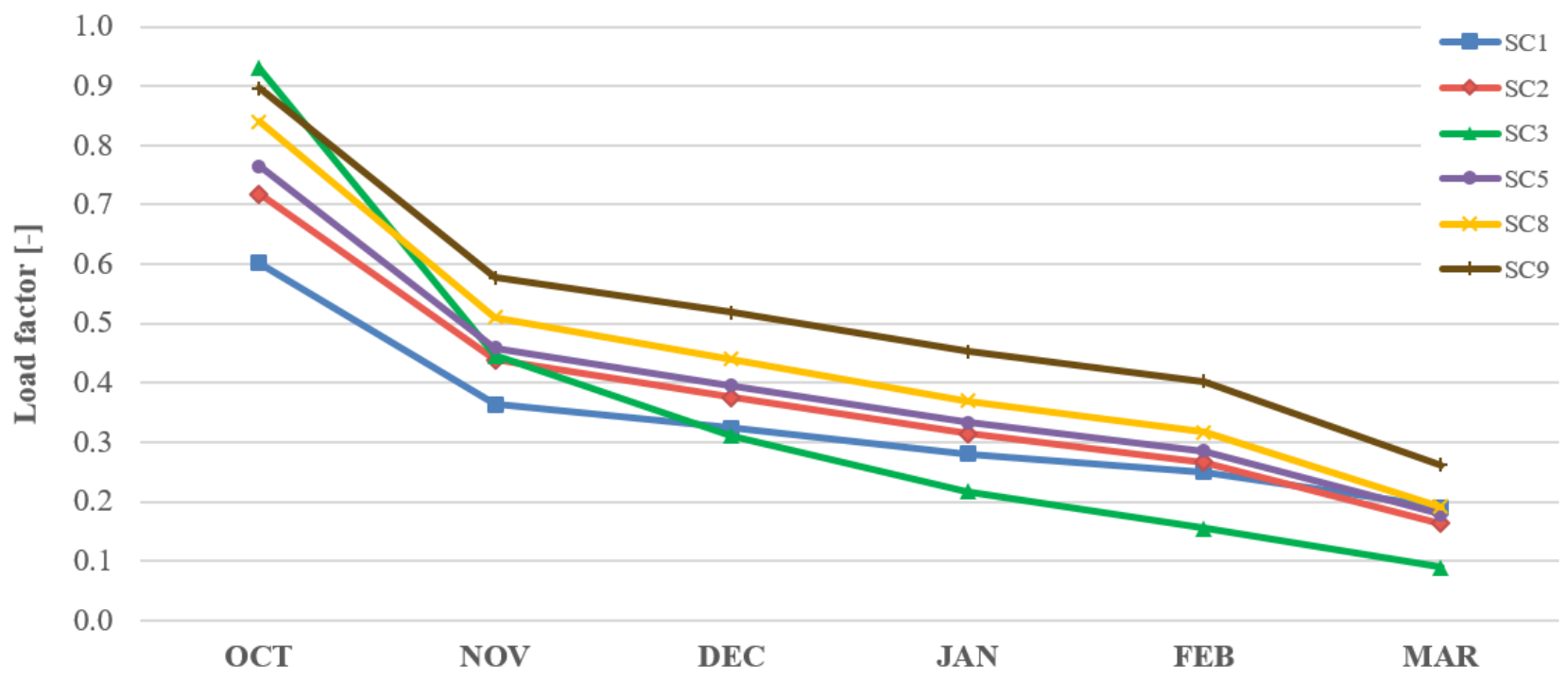

Figure 10 -Load factors of the most interesting scenarios at year 3.

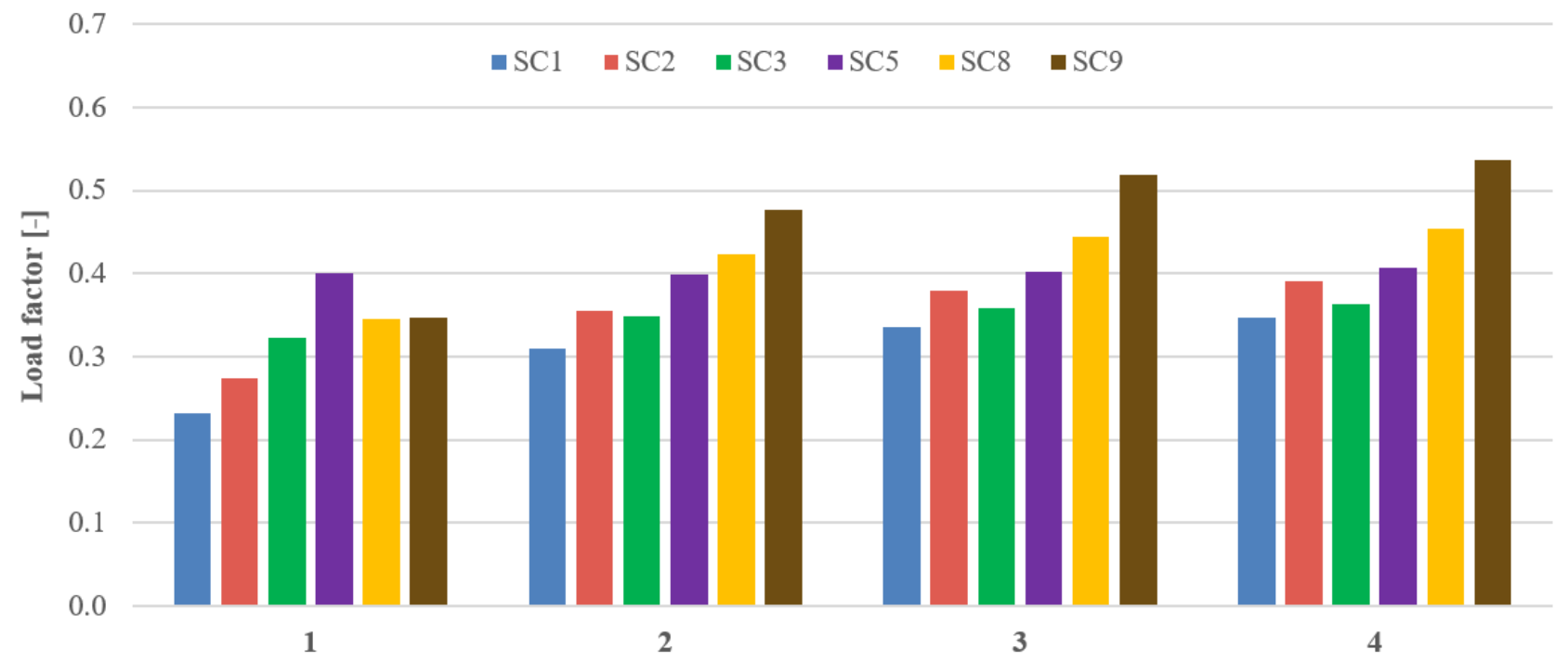

Figure 11 - Average load factors of the most interesting scenarios from year 1 to 4.

As expected, heat losses mainly take place through the side of the storage volume (ca. $70-80 \%$ ), followed by the bottom (ca. $15-20 \%$ ) and top (ca. $2-5 \%$ ), and these results are consistent in all the 11 scenarios (Fig. 12). As SC3 and SC6 generally showed the greatest amount of heat loss (see Tab. 5), they also show the highest percentage of side losses at the expense of the bottom. Diminishing heat losses from year 1 to 4 were observed in all scenarios, and the trend is driven by the losses through the sides as emphasized by the peaks in SC3 and SC6. Bottom and top losses keep the same absolute value throughout the simulation in both charge and discharge modes (e.g. Fig. 13). 


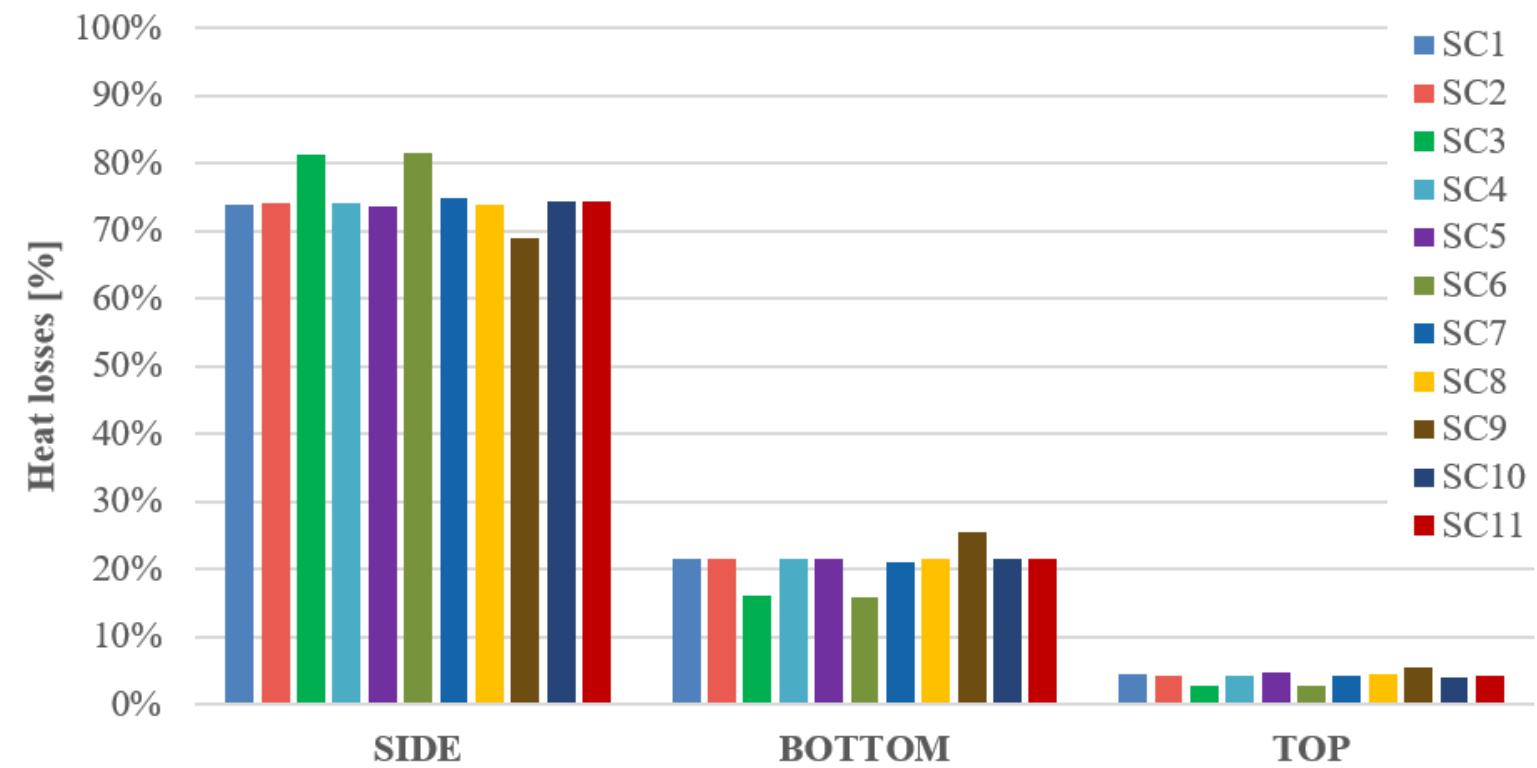

Figure 12 - Percentage heat loss through the side, bottom and top of the storage.

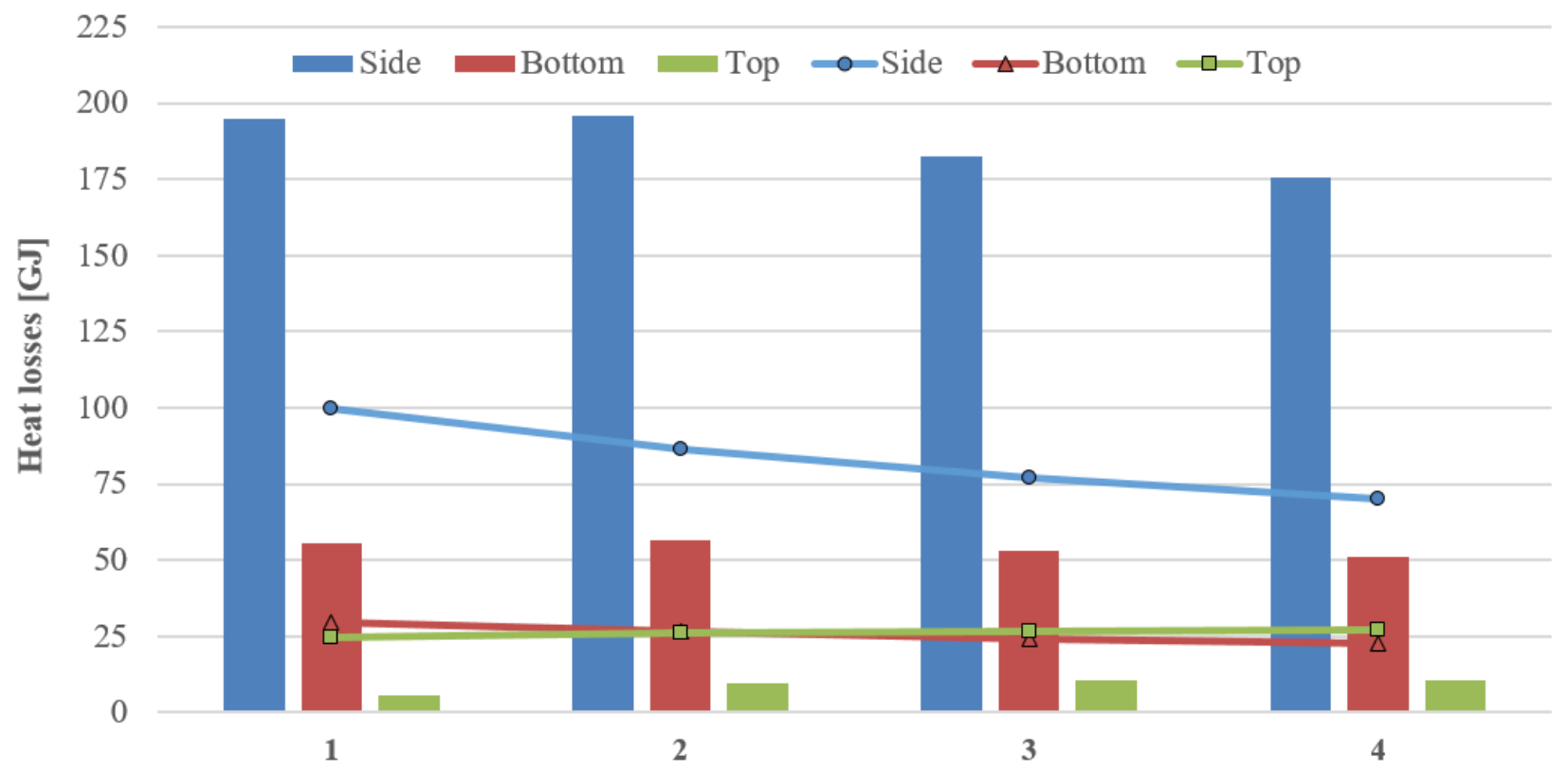

Figure 13 - SC2 heat loss during charge (bars) and discharge (curves) from year 1 to 4.

\subsubsection{Energy consumption}

The energy needs of the system differ slightly among all scenarios, except for SC9 and SC11 that show higher

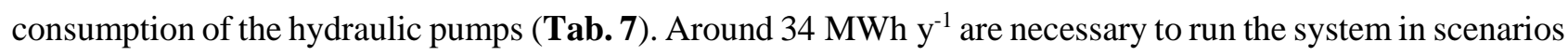
SC1 to SC7 and in SC10. About $6 \%$ more energy is consumed by SC8 (36 MWh) due to the increase in gross solar area. SC9 and SC11 need $47 \%$ more than the first scenarios (ca. $50 \mathrm{MWh}$ ) due to higher BTES flow rates. Indeed, the BTES loop accounts for $85 \%$ of the system's consumption, while water and solar loops contribute as little as $7 \%$. 
The operating costs of the BTES system would amount to approximately $7000 \mathrm{USD}^{-1}$ when considering the subsidised cost of electricity guaranteed by Hydro-Québec, but would range between 20000 to 30000 USD y $^{-1}$ if the real production cost was assumed [13,89]. The auxiliary system would cost from 40000 to 60000 USD annually, respectively considering subsidized and real cost. The operating costs of the existing diesel boilers amount to approximately 81000 USD annually (65 000 USD subsidised), considering the net calorific value of diesel as $38.3 \mathrm{MJ}^{-1}$ [90]. Around 540001 of diesel are necessary to run the system every year and approximately 141 tonnes of equivalent $\mathrm{CO}_{2}$ are released annually, with a GHG emission value for diesel at 2.64 tonnes eq. $\mathrm{CO}_{2} \mathrm{l}^{-1}$. Taking SC5 as reference scenario and considering the amount of diesel consumed to produce electricity (efficiency of the diesel power plant 0.35), a BTES system could generate annual savings of 70001 of diesel and 19 tonnes of equivalent $\mathrm{CO}_{2}$ (Tab. 8).

Table 7 - Average annual power consumption of the hydraulic pumps (BTES + solar + water loops) and operating costs of the auxiliary system.

\begin{tabular}{c|ccccc} 
& $\begin{array}{c}\text { Energy } \\
\text { consumption } \\
\text { (kWh) }\end{array}$ & $\begin{array}{c}\text { BTES subsidised } \\
\text { (USD) }\end{array}$ & $\begin{array}{c}\text { BTES real } \\
\text { (USD) }\end{array}$ & $\begin{array}{c}\text { Auxiliary subsidised } \\
\text { (USD) }\end{array}$ & $\begin{array}{c}\text { Auxiliary real } \\
\text { (USD) }\end{array}$ \\
\hline SC1 & 34086 & 6966 & 21876 & 49073 & 61116 \\
SC2 & 34479 & 7076 & 22128 & 45861 & 57115 \\
SC3 & 34503 & 7083 & 22144 & 47793 & 59521 \\
SC4 & 34410 & 7057 & 22084 & 45746 & 56972 \\
SC5 & 34472 & 7074 & 22124 & 44969 & 56004 \\
SC6 & 34612 & 7114 & 22214 & 51532 & 64177 \\
SC7 & 34608 & 7113 & 22211 & 52412 & 65274 \\
SC8 & 36065 & 7521 & 23146 & 42648 & 53113 \\
SC9 & 50853 & 11671 & 32637 & 39218 & 48842 \\
SC10 & 34497 & 7081 & 22140 & 44774 & 55762 \\
SC11 & 49381 & 11258 & 31692 & 46009 & 57300 \\
\hline
\end{tabular}

Table 8 - Average total annual costs (BTES + auxiliary), financial savings and GHG emission saving.

\begin{tabular}{c|ccc} 
& $\begin{array}{c}\text { BTES+Aux subsidised } \\
\text { (USD) }\end{array}$ & $\begin{array}{c}\text { BTES+Aux real } \\
\text { (USD) }\end{array}$ & $\begin{array}{c}\text { GHG saving } \\
\text { (t eq. CO })\end{array}$ \\
\hline SC1 & 56039 & 82992 & 10.8 \\
SC2 & 52937 & 79243 & 17.5 \\
SC3 & 54876 & 81665 & 13.3 \\
SC4 & 52803 & 79056 & 17.8 \\
SC5 & 52043 & 78128 & 19.4 \\
SC6 & 58645 & 86391 & 5.1 \\
SC7 & 59525 & 87485 & 3.2 \\
SC8 & 50169 & 76260 & 23.3 \\
SC9 & 50888 & 81478 & 20.3 \\
SC10 & 51856 & 77902 & 19.8 \\
SC11 & 57267 & 88992 & 6.6 \\
\hline
\end{tabular}




\subsubsection{Life-cycle cost analysis}

The 50-years LCCA was carried out on SC5. The results show similar NPC and LCOE for the BAU and the subsidised BTES scenario at the optimistic drilling cost, around 2 million USD and $0.21 \mathrm{USD} \mathrm{kWh}^{-1}$ in both cases, even if the capital cost of the latter is more than ten times bigger than BAU (Tab. 9). It is important to note that the annual costs of unsubsidised BTES scenarios are bigger than BAU. This occurs because, compared to BAU, the BTES system would require about $34 \mathrm{MWh}$ of electrical energy that would be produced by burning other diesel, thus preventing both BTES 37 and BTES 224 to approach BAU even in the long term (Fig. 14). The last scenario shows, however, that if the electricity was produced by solar PV the LCOE would be lower than $0.2 \mathrm{USD} \mathrm{kWh}^{-1}$, with a payback time of 15 years. Besides this, the annual GHG emission saving would amount to 44 tonnes of equivalent $\mathrm{CO}_{2}$ (ca. 170001 of diesel).

Table 9 - 50-years LCCA results of the five BTES scenarios compared to the BAU. Capital, annual and periodic costs are reported together with NPC and LCOE. SC5 was used for the calculation.

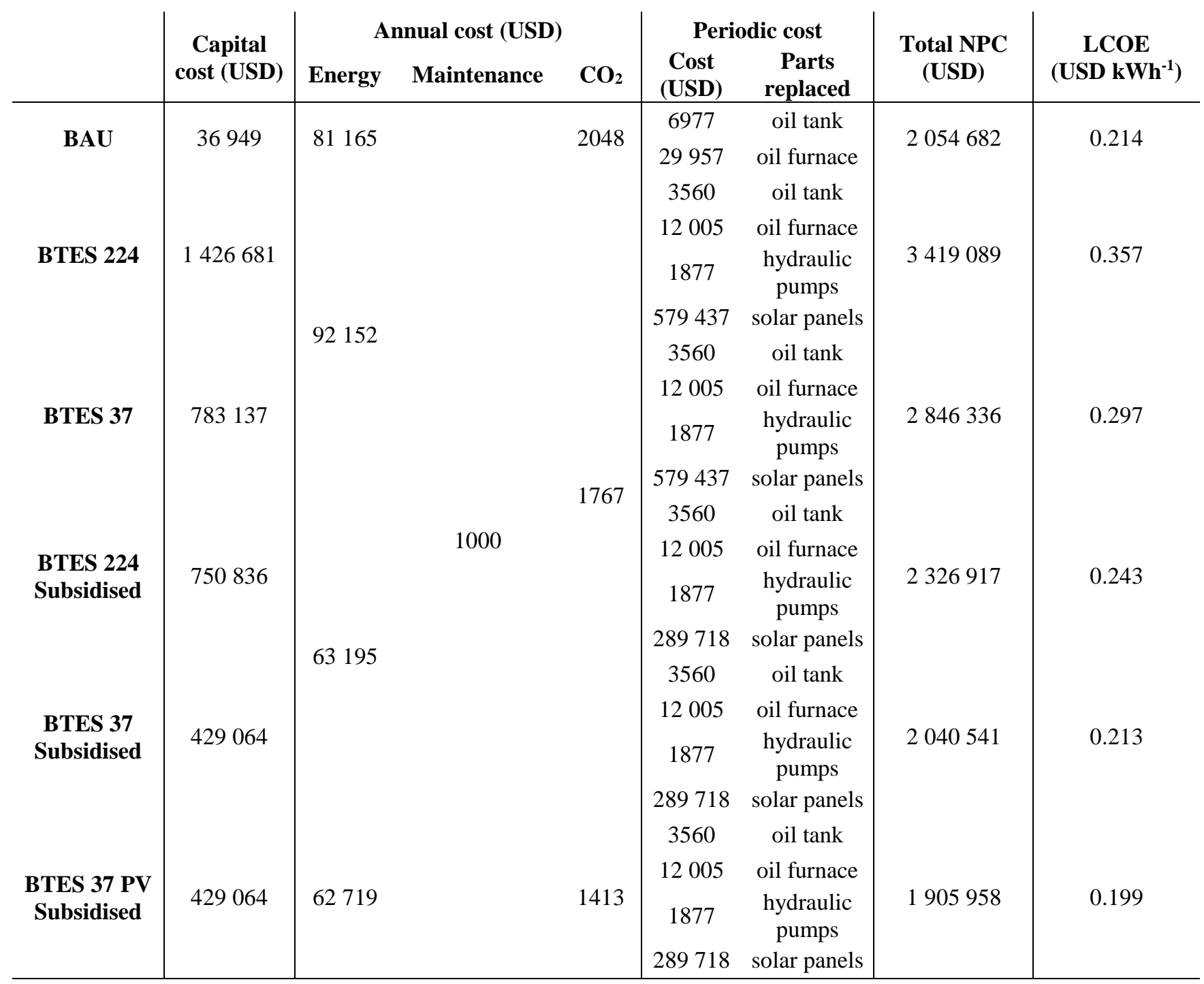




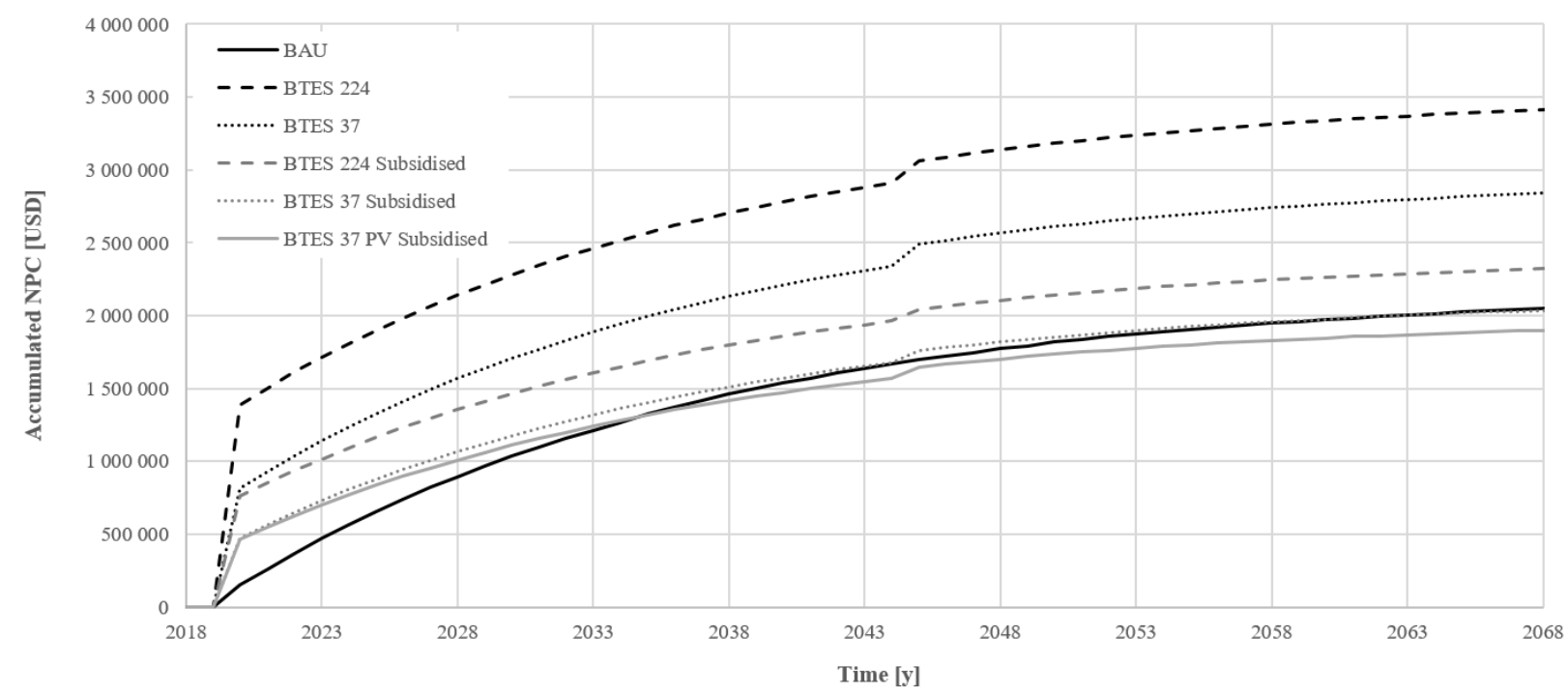

Figure 14 - Accumulated NPC of the five financial BTES scenarios compared to BAU over the 50 years.

\subsection{FEFLOW}

In an effort to evaluate the impact of groundwater flow, a number of observation points were set upstream and downstream of the storage centre in the direction of groundwater flow to assess the temperature distribution of the four scenarios. At a depth of $15 \mathrm{~m}$ (half the total depth), the following distances from the centre were considered: $0 \mathrm{~m}$ (centre), $10 \mathrm{~m}$ (edge), $20 \mathrm{~m}$ (out), $30 \mathrm{~m}$ (far) in scenarios A, C and D; scenario B has the same names but distances of $0,10,25$ and $35 \mathrm{~m}$. The four scenarios show maximum temperature values reached by the underground storage of $15-16^{\circ} \mathrm{C}$ (scenario A) and $10-11{ }^{\circ} \mathrm{C}(\mathrm{D}$; Fig. 15). Differences in the distribution are related to the volume and shape of the storage, and the injection mode. In the conventional circular shaped volumes, warmer core and significant stratification are easily achievable: the ground in A reaches a higher temperature than B because energy in the latter is distributed over a greater ground volume. In square-shaped systems, the temperature distribution is more homogeneous and a warm core is difficult to obtain. However, the ground temperature differences are more evident in $\mathrm{C}$ compared to $\mathrm{D}$, where injection occurs in the upstream boreholes (see Fig. 6): alternating the BHE connection in scenario D reduces the stratification because groundwater flow distributes energy homogeneously within the storage volume.

In general, the ground store stops warming before the end of the charge phase, and the centre peaks at $5200 \mathrm{~h}$ (A, B, early August) and $6000 \mathrm{~h}$ (C, D, early September), which is also the case with the TRNSYS simulations. As highlighted in Section 2, August has a mean solar radiation of about $4 \mathrm{kWh} \mathrm{m}^{-2} \mathrm{~d}^{-1}$ and September has $3 \mathrm{kWh} \mathrm{m}^{-2} \mathrm{~d}^{-1}$, while the other four charging months produce approximately $5 \mathrm{kWh} \mathrm{m}^{-2} \mathrm{~d}^{-1}$ (see Fig. 2). The charge power of the BTES system is obviously affected by a smaller solar production of the collectors. As expected, the maximum temperature at the end of the charge phase is recorded by the edge_down observation point ( 10 or $15 \mathrm{~m}$ downstream of the centre) in all the scenarios due to groundwater advection, but differences can be noticed between circular and square shape volumes (Fig. 16). In A and B, edge_down overtakes centre in early/mid-August; this occurs already at the beginning in $\mathrm{C}$ and $\mathrm{D}$, with the latter showing similar values 
throughout the charge period. Scenario A displays out_down $\left(12^{\circ} \mathrm{C}\right)$ significantly warmer than half the storage upstream $\left(6^{\circ} \mathrm{C}\right.$, edge_up $)$ at the end of the charge, and even far reaches $9{ }^{\circ} \mathrm{C}$ after half the discharge. This is similar but less evident in the other scenarios because differences between centre and edges are less important, in particular in the square-shaped storage volumes (C, D; Fig. 15). At the end of the discharge phase, a significant amount of energy has moved out of the storage volume in all the scenarios. Far and out_down display $8{ }^{\circ} \mathrm{C}$ and $6{ }^{\circ} \mathrm{C}$ in $\mathrm{A}, 6{ }^{\circ} \mathrm{C}$ and $5{ }^{\circ} \mathrm{C}$ in $\mathrm{B}, 6{ }^{\circ} \mathrm{C}$ and $4{ }^{\circ} \mathrm{C}$ in $\mathrm{C}$ and $\mathrm{D}$, which are up to $2{ }^{\circ} \mathrm{C}$ warmer than centre and edge_down.

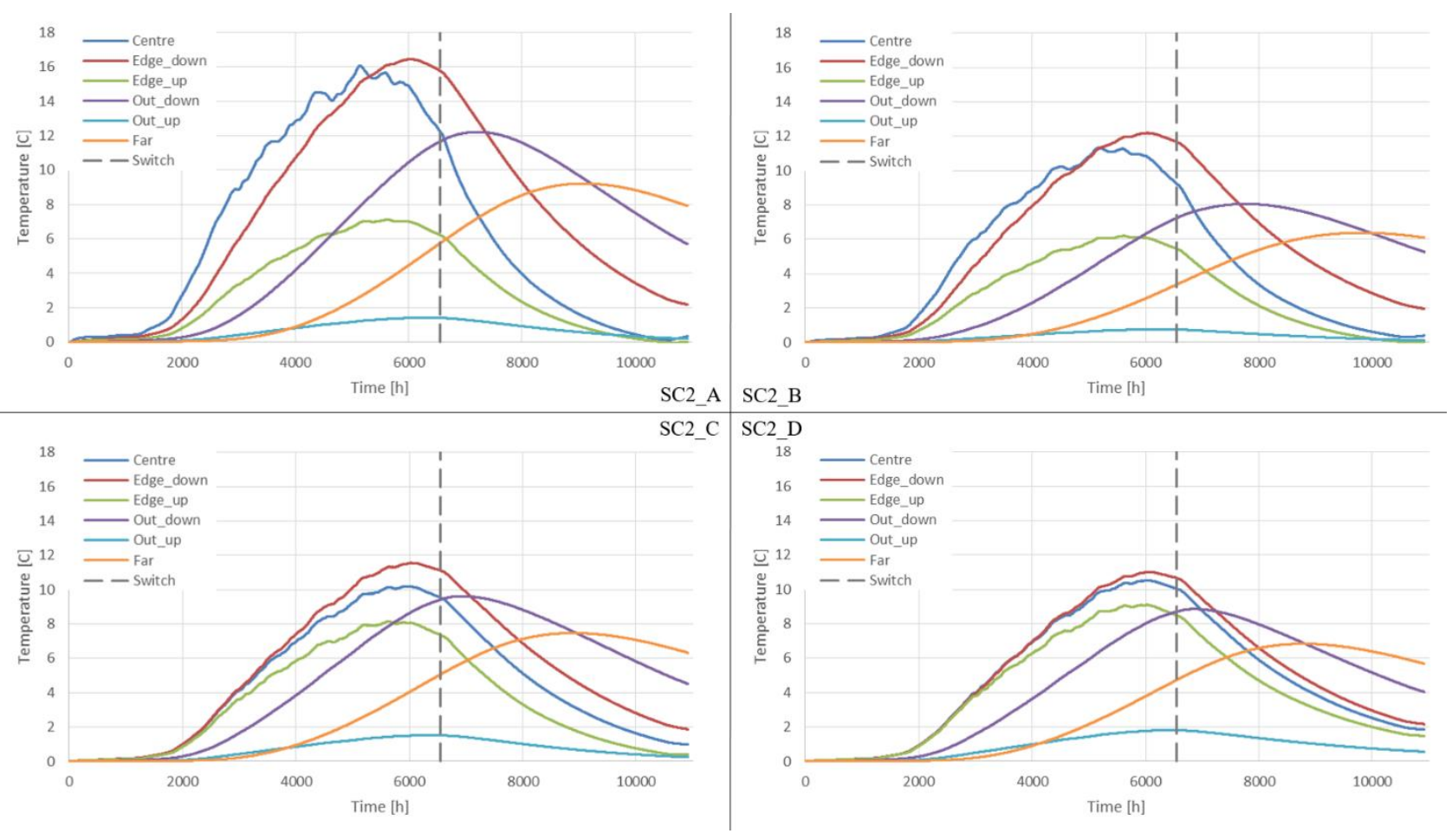

Figure 15 - Subsurface temperature values at $15 \mathrm{~m}$ depth simulated with FEFLOW for four scenarios. The dashed grey line marks the switch from charge to discharge. 

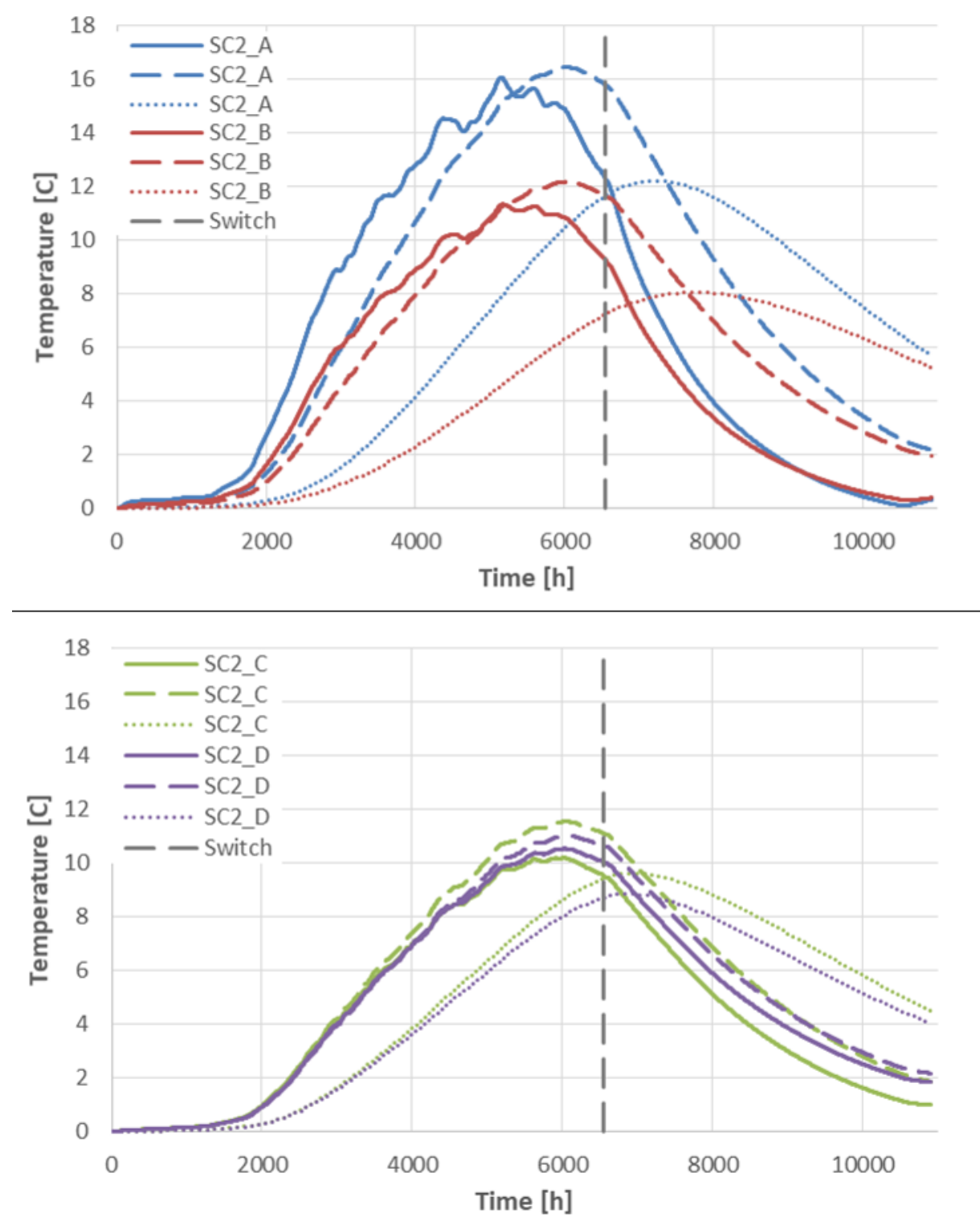

Figure 16 - Comparison of the subsurface temperature values simulated with FEFLOW for four scenarios. The continuous, dashed and dotted lines represent the centre, edge_down and out_down locations, respectively, as in Fig. 15.

The amount of energy stored in the ground volume differs among scenarios, with B storing more than $1000 \mathrm{GJ}$ at the end of the charge phase, $\mathrm{C}$ and D little more than $900 \mathrm{GJ}$, and A only 876 GJ (Tab. 10). As a consequence, scenario B performs best in limiting heat loss caused by groundwater advection (18\%), due to its volume of $35000 \mathrm{~m}^{3}$ which makes it possible to keep $22 \%$ more energy than A ( $32 \%$ heat loss). The square-shaped volumes (ca. $28 \%$ heat loss) behave better than A, without showing any significant difference between them. Conversely, the newly proposed alternate connection of scenario D yields the expected benefits during the discharge mode with the smallest amount of heat loss $(11 \%, 38 \%$ and $41 \%$ less than C, A and B, respectively). Losses during the discharge must be considered as the ability of the BHE shape and connection to retrieve previously stored energy: scenario B loses the highest amount of energy due to the wide BHE spacing (3.8 m, see Tab. 4); scenario D takes advantage of the unconventional BHE connection to collect the 
amount of energy stored in the half-downstream part of the storage and allows only 174 GJ to disperse. In terms of HR, the highest value (43\%) in SC2_A is caused by the smallest amount of storage volume.

Table 10 - Summary of the results obtained with FEFLOW simulations (A to D) and comparison with the TRNSYS reference scenario (SC2). Injection (1292 GJ) and extraction (376.6 GJ) are common to all four scenarios.

\begin{tabular}{c|ccc|cc} 
& \multicolumn{3}{|c|}{ CHARGE } & \multicolumn{2}{c}{ DISCHARGE } \\
& Storage & \multicolumn{2}{c}{ Losses } & Losses & $\boldsymbol{\eta}_{\text {BTES2 }}$ \\
\cline { 2 - 6 } & GJ & GJ & $\%$ & GJ & $\%$ \\
\hline SC2_A & 876.2 & 415.7 & 32.2 & 278.3 & 43.0 \\
SC2_B & 1065.3 & 226.9 & 17.6 & 294.4 & 35.4 \\
SC2_C & 928.0 & 364.2 & 28.2 & 195.3 & 40.6 \\
SC2_D & 936.5 & 355.7 & 27.5 & 173.8 & 40.2 \\
\hline SC2* & 1021.2 & 271.1 & 21.0 & 153.7 & 36.8 \\
\hline
\end{tabular}

* Values are different than in Tab. 6 because the energy injected (ca. 130 GJ) and lost (ca. 15 GJ) from January to March has been included to be easily comparable with data from FEFLOW

Comparing the results from the two simulation approaches revealed that scenarios A, C and D lose $11 \%, 7 \%$ and $6.5 \%$ more energy than theSC2 reference TRNSYS case in the charge phase; scenario B with a larger volume manages to perform $3 \%$ better (Tab. 10). Also during the discharge, all the FEFLOW scenarios show higher energy loss, from a minimum of $13 \%$ (D) to a maximum of $48 \%$ additional heat loss (B). Again, HR is higher in scenarios A, C and D because the same amount of extraction is compared to smaller storage values achieved during the charge phase. Moreover, marked differences caused by groundwater advection can be noted in the temperature distribution (Fig. 17). TRNSYS indicates higher peaks and the centre value is always warmer than the edge. Interestingly, temperature distribution obtained with FEFLOW returns to the initial value, at least within the BHE field, while ground temperature always remains $7-8{ }^{\circ} \mathrm{C}$ warmer with TRNSYS. The gap is almost entirely related to the amount of energy lost due to groundwater flow since the energy extraction is exactly the same in the two simulations ( $377 \mathrm{GJ})$ and the main design parameters for the underground storage are identical (number of BHEs, shape, volume, BHE connection). Nevertheless, temperature differences can also be related to the different approaches used by the two codes to solve the heat transport problem in the boreholes: FEFLOW uses the Eskilsson's analytical solution [84] whereas TRNSYS is based on the numerical Hellström's DST model [79] (see Section 3). Moreover, boreholes are uniformly spaced in the ground volume when using TRNSYS, whereas manually-set disposition with FEFLOW has constant spacing between boreholes belonging to the same series only, which can partly explain the different simulation results. These last two elements were not accounted for because it was beyond the scope of the present contribution. 


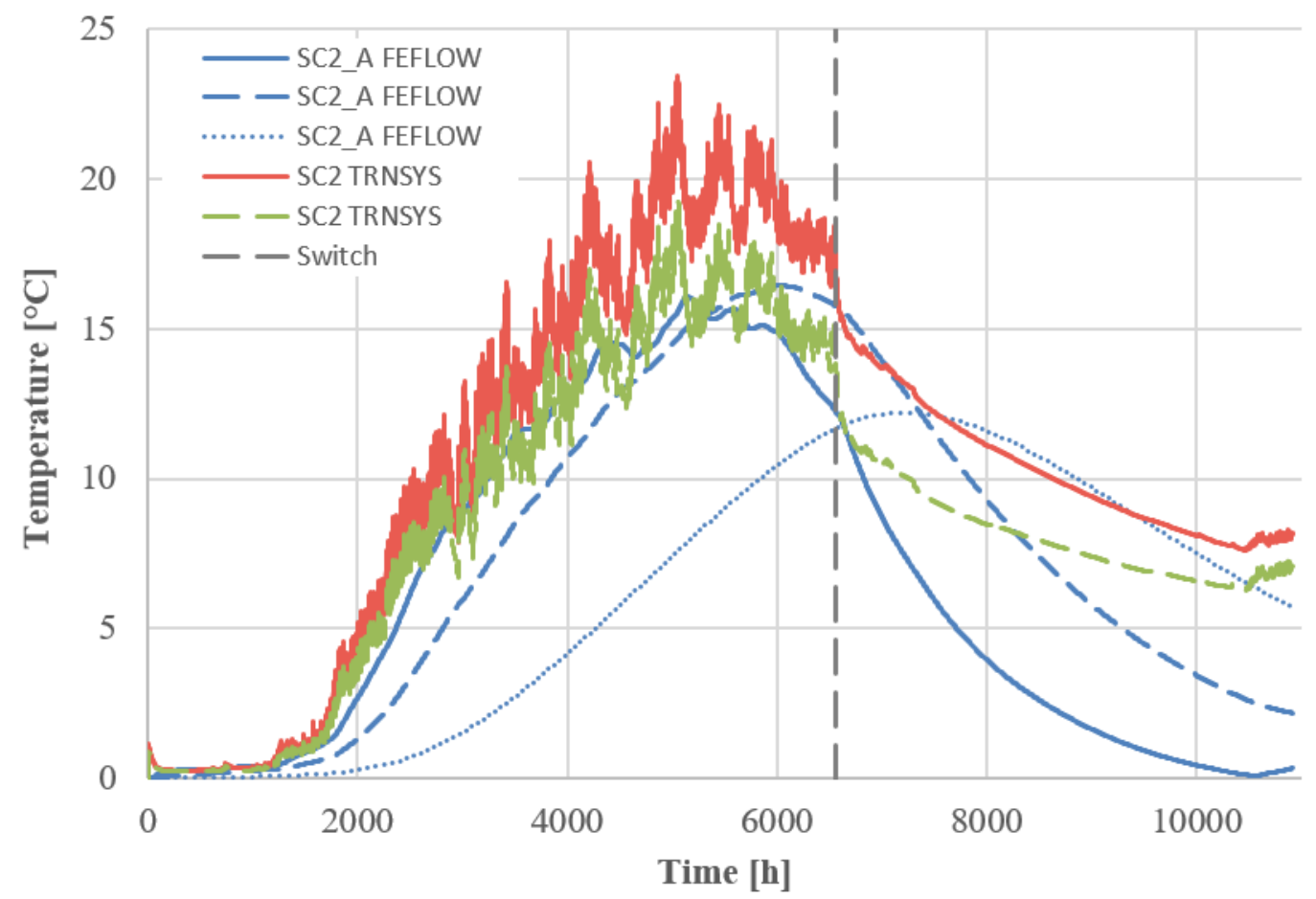

Figure 17 - Underground temperature distribution simulated with FEFLOW for SC2_A (downstream values plotted) and TRNSYS for SC2. Note that the edge FEFLOW value (dashed blue curve) is closer to centre than the edge value in TRNSYS (dashed green curve).

The ability to reduce heat loss by increasing storage volume was confirmed by both TRNSYS and FEFLOW simulations: SC2 (27\%) and SC7 (28\%) have better results than the corresponding SC3 (34 \%) and SC6 (33\%) with smaller ground volumes; SC2_B loses only $18 \%$ with respect to $32 \%$ observed in SC2_A. Nevertheless, large subsurface volumes affect energy retrieval during the discharge if the BHE spacing is not well suited to the site's thermal conductivity: SC7 (4.1 m spacing) recovers less energy than SC6 (2.7 m), whereas SC2 $(2.9 \mathrm{~m})$ retrieves more than SC3 $(1.9 \mathrm{~m})$. Therefore, a spacing of around $2.5-3 \mathrm{~m}$ seems to be the best option for the present site, slightly higher than what was found by [76].

\section{Discussion}

Eleven BTES scenarios were simulated to optimize the performance of the system facing a subarctic climate and cover $50 \%$ of the heating demand for drinking water pumped at Stewart Lake during winter. Only two scenarios reach $50 \% \mathrm{SF}$ at the end of the simulation (SC8 and SC9), but an additional $500 \mathrm{~m}^{2}$ of gross solar area is needed with respect to the base case scenario. Nevertheless, several design elements were modified to improve the storage-retrieve cycle without adding solar collectors or increasing the drilling length, which represent the most expensive adjustments. The best SF improvement from the base case (SC1) is achieved by adding a second STST that allows greater energy extraction (SC2). Moreover, halving the storage volume increases the HR (SC3), but the amount of energy retrieved during the discharge clearly drops due to the greatest energy loss (34\%) among all the scenarios. Using the second STST only during the discharge (SC4) did allow the system to collect, store and extract more energy, but by only a few GJ over the season. One year 
of pre-heating (SC5) is clearly appropriate, particularly because the system starts working at its maximum capacity and, in the first year, already reaches in the first year HR $\left(\eta_{\mathrm{BTES} 1}=61.7 \%\right), \mathrm{SF}(43.8 \%)$ and load factor (0.4) that the previous scenarios are unable to reach by the last year of simulation. Smaller and cheaper underground storage volumes were also tested in SC6 and SC7: even if the BHE field appears under-designed for the $1000 \mathrm{~m}^{2}$ solar collector area $\left(\eta_{\mathrm{SOLAR}}=21\right.$ and $24 \%$ respectively), around $30 \%$ of SF could be reached, a little less than SC1 but possibly translating into important savings in the drilling activities. As anticipated, SC8 and SC9 achieve the best SF, $49 \%$ and $57 \%$ at year 3, respectively, but HR values are not significantly better than SC2 or SC5, and in some cases even lower. Last technical adjustments were adopted to increase the Reynolds number in the BHEs by decreasing the refrigerant in the HCF (SC10) and by increasing the BTES loop flow rate (SC11). The same results as SC10 can be reached with SC4 or SC5 without risk of freezing the heat carrier fluid, as the freezing point of $25 \%$ vol. propylene glycol $\mathrm{HCF}\left(-11^{\circ} \mathrm{C}\right)$ is definitely unsuited for temperatures experienced in Kuujjuaq. However, the improvements noted in SC10 are minimal compared to the significant loss occurring through the heat exchanger, making this option useless. Finally, a turbulent flow was not reached in SC11 with $60 \mathrm{~m}^{3} \mathrm{~h}^{-1}(\operatorname{Re} 2100)$, while at least $120 \mathrm{~m}^{3} \mathrm{~h}^{-1}$ would be necessary with BHEs of the same design parameters ( $R e$ 4400). This would, however, raise the average annual power consumption to 93 MWh (34 MWh in SC2) and the subsidised operation costs to about 26000 USD y $^{-1}$, without considering that larger STST would probably be needed to handle this flow rate.

All the scenarios were compared in terms of HR and SF as proposed by Flynn and Sirén [36]. SC8 and SC9 show the best SF due to the larger solar area and underground storage volume (Fig. 18). SC10, SC2 and SC11 follow the same pattern, and SC5 has about the same values, showing that an equilibrium is already reached at year 1. SC3 displays the best recovery in the last years, but, together with the other scenarios, does not reach $40 \% \mathrm{SF}$. The highest recovery in SC3 is explained by the smallest volume-to-gross-solar-area ratio $\left(9.5 \mathrm{~m}^{3} \mathrm{~m}^{-2}\right)$, making it comparable to an experimental BTES used to heat a greenhouse in Shanghai (CN) described by Xu et al. [91]: that system showed $\eta_{\mathrm{BTES} 1}=63 \%$ in the first year, whereas SC3 reaches $49 \%$, $60 \%, 63 \%$ and $64 \%$ in years 1, 2, 3 and 4, respectively. This match demonstrates that small volumes - those that can provide high heat recovery and very high load factors in the first months - can be useful for short heating season applications such as greenhouses [44].

SC2 performance evaluation was plotted against three systems simulated by [36], which studied the residential BTES operating at Drake Landing Solar Community (DLSC; [29]) and modelled the same system in five other different locations. The coldest locations were chosen for comparison to Kuujjuaq, even though they are not as cold: Helsinki $\left(60^{\circ} \mathrm{N}, 4600 \mathrm{HDD}_{18}, \mathrm{FI}\right)$, Hohhot $\left(41^{\circ} \mathrm{N}, 4630 \mathrm{HDD}_{18}, \mathrm{CN}\right)$ and DLSC in Okotoks $\left(50^{\circ} \mathrm{N}\right.$, $\left.4930 \mathrm{HDD}_{18}, \mathrm{CA}\right)$. SC2 performs better than all of them in terms of heat recovery, with $\eta_{\mathrm{BTES}}$ higher than $50 \%$ in the second year, although SF remains lower. Finally, results from these simulations also show solar efficiency suitable for some operating plants in much warmer climates. As an example, at year 1, DLSC provided $\eta_{\text {SOLAR }}=33 \%$ [29], Braedstrup (DK) $\eta_{\text {SOLAR }}=36 \%$ [30,82], while SC2 displays $33 \%$. 

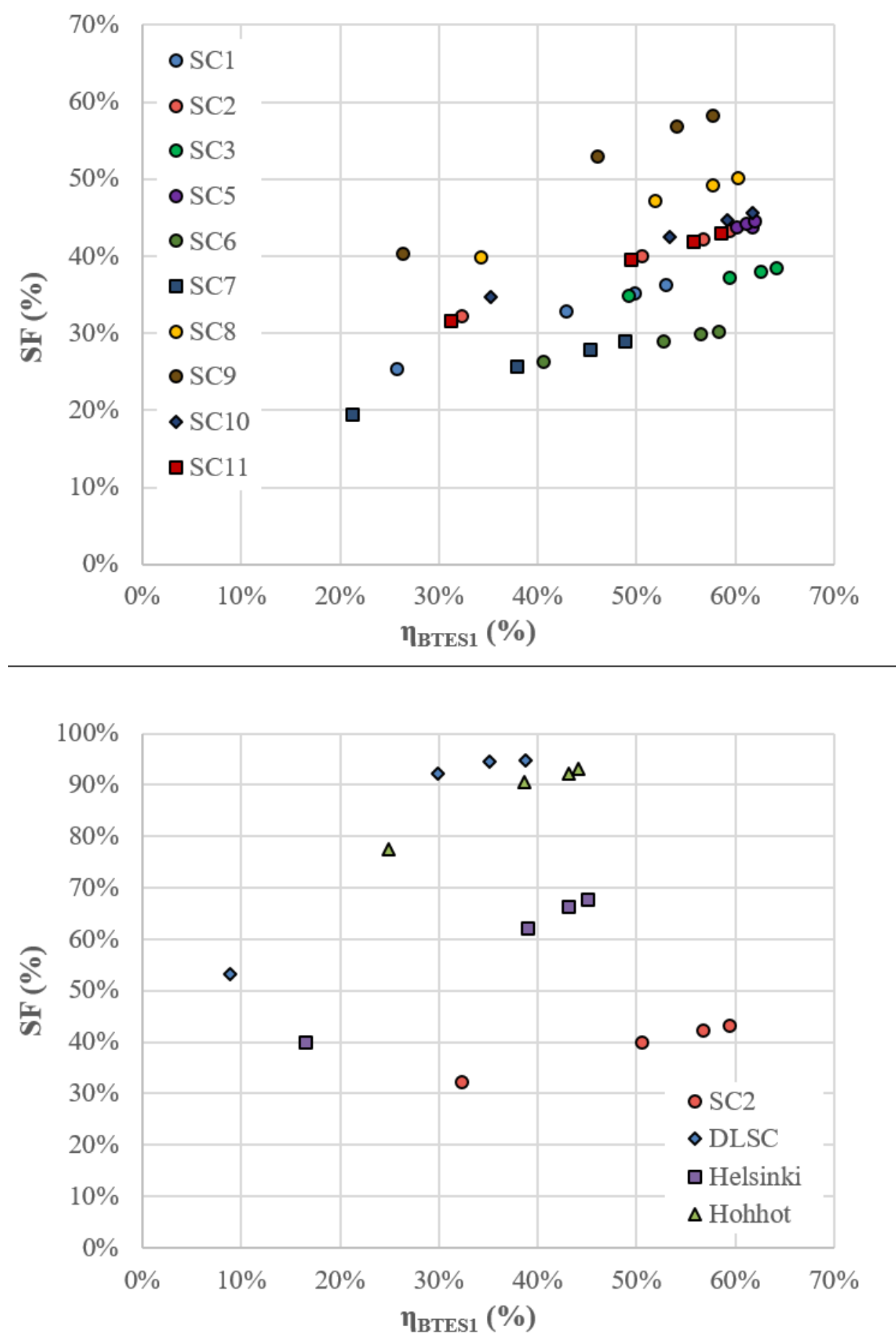

Figure 18 - Above: system recovery plotted against solar fraction for the simulated scenarios (SC4 is not shown as it superimposes SC2). Below: comparison of SC2 with systems in Okotoks (DLSC), Helsinki and Hohhot.

The best scenario for the pumping station in Kuujjuaq is SC5 that reaches $45 \%$ of SF, with $\eta_{\mathrm{BTES}}=62 \%$, $\eta_{\mathrm{BTES} 2}=83 \%$ and $\eta_{\text {SOLAR }}=30 \%$ at the end of the simulations. It is clear that the largest financial investment necessary for SC8 (+50\% of solar area) and SC9 (+50\% in both solar area and total drilling length) to achieve better SF than SC5 would not be worthwhile. Similarly, the savings achievable in SC6 or SC7 by halving the total drilling length would not justify these options for the Kuujjuaq site. This conclusion holds even without taking into account the subsurface heat loss due to groundwater advection, which the FEFLOW simulations 
showed can amount to an additional $11 \%$ (SC2_A) at this specific site. However, energy extraction simulated with TRNSYS in the first year allows the subsurface to return close to the initial temperature distribution, without extracting a surplus of energy from the subsurface. It should be noted though, that the energy extraction in SC2 progressively increases towards the end of the simulation, being almost $44 \%$ more in year 4 (see Tab. 6). This issue could not be addressed in this study, but warrants further evaluation.

The impact of groundwater flow that can dissipate thermal energy injected by a BTES has been investigated by recent studies. For example, Nguyen et al. [56] evaluated the effect of groundwater flow and air temperature on the performance of a BTES, by applying a spectral method approach to transfer $g$ functions obtained by finite element modelling. The study confirmed that the BTES performance is considerably affected by groundwater flow when Darcy velocity is higher than $4 \mathrm{~cm} \mathrm{~d}^{-1}$ and they calculated that the outlet BTES temperature during the heating season is $27^{\circ} \mathrm{C}$ lower than the case with no flow. They also found that groundwater effect is much more important than seasonal variation in ground surface temperature. Groundwater advection was also pointed out as a serious barrier to efficient BTES operation by Rapantova et al. [34], even if the square-shaped storage in Paskoy (CZ) is influenced by only a 5-m-thick highly permeable Quaternary layer, which was considered negligible over the total $60 \mathrm{~m}$ of low permeability claystones. The advection effect was observed in both the recorded temperature data and the numerical observations. Bauer et al. [58], Diersch et al. [59] and Mielke et al. [57] all modelled the subsurface thermal influence of the circularshaped BTES operating in Crailsheim (DE) using a detailed geological and hydrogeological characterization of the site. The underground storage sits in fractured media with alternating aquitards (mud/wackestone; hydr. cond. $10^{-11} \mathrm{~m} \mathrm{~s}^{-1}$ ) and moderately permeable aquifers (grainstone; hydr. cond. $10^{-5}-10^{-6} \mathrm{~m} \mathrm{~s}^{-1}$ ). Mielke et al. [57] calibrated the model with experimental recordings and then predicted the BTES behaviour over a period of 30 years. However, in both [59] and [57] the focus was on temperature distribution because the aim was to evaluate the impact of groundwater flow on the extension of the thermally affected zone around the subsurface storage. Among all these studies, only [58] quantified advection heat loss, calculating a maximum reduction in heat recovery of $1.9 \%$ at year 4 when groundwater flow was taken into account. It can be said that this value is in agreement with the results of the present study, considering that aquifers in Crailsheim affect less than half the storage depth.

In summary, this study has demonstrated that an analysis of storage shape, borehole spacing and borehole connections can be beneficial in optimizing BTES performance under groundwater flow conditions. The results highlight that a square-shaped volume, such as the one designed in Paskoy [34], limits heat loss during the charge phase better than a conventional circular scheme when the system is influenced by groundwater flow (60\% less than SC2_A). Moreover, the newly-proposed alternating BHE connection (SC2_D) can mitigate advective heat loss during the discharge (50\% less than SC2_C). Groundwater flow characterization may not be simple or straightforward. But this contribution shows that detailed characterisation and accurate design of BHE disposition at sites with strong advection can significantly reduce heat loss and improve the overall performance of system. 
Finally, the limitations of the study mainly pertain to the uncertainty of thermal property characterization and the assessment of groundwater flow velocity and direction. On the one hand, thermal conductivity and heat capacity were estimated with $13 \%$ and $6 \%$ uncertainty, respectively (see Section 3.1), and their spatial validity can be extended to the whole simulated subsurface with a high confidence level. On the other hand, the hydrogeological considerations are based on field surveys performed at a specific time of the year (early July) and therefore carry a higher degree of uncertainty. Nevertheless, the results are assumed to be conservative: since the snow usually melts in June, the groundwater level was therefore most likely at its highest elevation during the field campaign, and thus hydraulic gradient and Darcy velocity were at their peak. Less relevant limitations include the lake temperature (assumed as monthly constant, see Fig. 8) and the maintenance of the solar collectors' surface as described in Section 3.3. However, an in-situ monitoring system that records data throughout the season could reduce the most important uncertainties and would therefore be a key step to implement before setting up a demonstration system. It should be emphasized that the BTES presented here is located at a site that is free of frozen ground due to specific local geological and hydrogeological conditions (see Section 3.1). Besides Kuujjuaq, some other southern Nunavik communities are situated in areas of sporadic (Whapmagoostui-Kuujjuaraapik) and discontinuous permafrost (e.g. Umiujaq, Kangiqsualujjuaq, Tasiujaq) [65], and these zones are likely to extend further north given the warming trend [60]. That being said, the results of this study can be considered valid for such communities, where similar sites can be identified for the deployment of BTES technology, now that it has been shown to be viable in a subarctic environment that is colder than any previous works considering BTES.

\section{Conclusions}

The present paper shows the five-year thermal response of a borehole thermal energy storage (BTES) in an off-grid subarctic community in northern Canada. To the best of the authors' knowledge, this is the first seasonal underground storage study carried out in an area where the space heating demand is characterized by more than 8000 heating degree days below $18{ }^{\circ} \mathrm{C}$. After describing the general setting of the study area, the geological conceptual model is defined and the BTES design outlined. Model set-up and results of the simulations carried out with the software TRNSYS and FEFLOW are then presented. Finally, a comparison with other similar plants is discussed to evidence challenges of operating BTES in the Arctic.

The modelled BTES system displays higher heat recovery (HR) and similar solar efficiency than analogous applications in warmer climates, but lower solar fraction (SF). This is an important finding that should stimulate BTES installations further north. It also indicates that, although SF is likely to decrease with latitude, efficient energy storage can still be achieved in the ground with undisturbed near-freezing conditions. The present study demonstrates for the first time that the subarctic climate of northern latitudes is not a limitation to the HR of BTES. SF can be increased easily by extending the solar area, but financial constraints come up and detailed cost-benefit analyses are needed to determine optimum techno-economic performance. The 50years life-cycle cost analysis showed that, despite the significant uncertainty related to the drilling and installation cost of BHE in Nunavik, provincial, federal and intra-national interventions are necessary to 
increase energy security in the Arctic and help develop BTES systems that would guarantee reductions in both diesel consumption and greenhouse gas emissions. Net present cost (NPC) and levelized cost of energy (LCOE) of BTES in the Arctic could be further reduced by evaluating, for example, the use of air-liquid [92] and photovoltaic solar collectors [93] that would avoid using propylene glycol in the heat carrier fluid, thereby improving the overall system performance. Moreover, photovoltaic panels could also cover part of the $34 \mathrm{MWh}$ of electricity necessary to run the BTES and further diminishing the annual use of diesel. As demonstrated here, this option would guarantee the best NPC, LCOE and $\mathrm{CO}_{2}$ emission saving. The positive results of the present study should generate interest in the construction of a BTES demonstration plant in Nunavik, which would in turn stimulate further progress towards $100 \%$ renewable Arctic in the near future.

Permafrost is not an issue at the Stewart Lake pumping station, but it can be present in other areas of the village and to the north of the discontinuous permafrost zone. For this and similar places, further studies would be needed to avoid degrading the frozen ground that provides stability for the foundations of buildings in cold climates. Strong groundwater flow generates additional advective heat losses that were quantified in this study by complementary thermo-hydrogeological simulations. The BTES thermal load outputs were used as input in FEFLOW to simulate the system's interaction with local groundwater flow. This first-level coupling made it possible to compare different storage shapes and borehole connections, and proved that a square storage with a newly-proposed borehole connection can help limit the amount of thermal energy lost by advection. This novel type of circulation could also be beneficial in other BTES systems operated under the influence of groundwater advection in temperate climates. However, further development of tools such as those used in $[57,59]$ are of paramount importance for more advanced coupled analyses.

Future activities should be directed towards the design of underground storage systems for greenhouses and medium-sized buildings in Kuujjuaq and other arctic villages facing the same energy issues. Moreover, according to the definition of Gibb et al. [39], both greenfield and retrofit applications can be deployed in Nunavik. Therefore, detailed analyses of energy storage process integration as well as environmental and economic life-cycle cost assessments at the single-process or community scale would be paramount to determining the actual benefits to the community, and, most importantly, involving all local stakeholders.

\section{Acknowledgments}

The authors would like to thank the Institut Nordique du Québec for supporting the research through the Northern Geothermal Potential Research Chair awarded to the second author. The sustainable mining development program of Fonds de recherche québécois - nature et technologies, and the Observatoire Homme Milieu Nunavik have additionally contributed to this research. The Centre d'études nordiques, the Nunavik Mineral Exploration Funds, the Makivik Corporation and the Kativik Regional Governments are acknowledged for their help with field logistics. Thanks to Inès Kanzari, Mafalda Miranda and Chrystel Dezayes for contributing to the field campaign in Kuujjuaq, and particularly to the first two who analysed the thermal properties of the Quaternary deposits. Last but not least, thanks to Evelyn Gunawan for her contribution to the LCCA. 


\section{Supplementary material}

Given the large amount of data obtained from the simulations, only the most important results were presented in this manuscript. Should the reader be interested in accessing additional data, the authors made some supplementary material available with the publication.

\section{Appendix A}

Taxes: A $14.98 \%$ Québec sales tax was applied to all costs.

Price and lifetime of equipment: The price of $10 \mathrm{~m}^{3}$ oil tank is $5000 \mathrm{USD}$, which has an expected lifetime of 25 years. The price of a $100 \mathrm{~kW}$ boiler is 12000 USD and a lifetime of 15 years. The price of the $100 \mathrm{~m}^{3}$ water tank is 20000 USD, which has an expected lifetime of 50 years. The price of 0.3 and $3.3 \mathrm{~kW}$ hydraulic pumps is 250 and 1000 USD, respectively, which have an expected lifetime of 25 years The lifetime of the heat exchanger is assumed to be 50 years. The cost of solar panel installation, which includes both labour and equipment is assumed to be at a higher end at $3.7 \mathrm{USD} \mathrm{W}^{-1}$ in Kuujjuaq. The lifetime of solar panel is assumed to be 25 years.

Labour wage and installation time: The average wage for 13 maintenance and technician jobs in Kuujjuaq was 19.64 USD [94]. It takes two working days for boiler installation, one working day for tank installation and 1 week for the hydraulic installation of the BTES system.

Maintenance: Maintenance for all heating scenario is assumed to be conducted annually at 1000 USD for diesel furnace system and 500 USD for the water tanks. Since in the BTES scenarios the furnace is only used to cover on average the $50 \%$ of the total energy demand, its maintenance cost in these cases was halved. Therefore, the total maintenance cost was assumed to be the same in the three options.

Shipping: Shipping of all the material from Québec City is provided by NEAS cargo shipping company at approximately $0.86 \mathrm{USD} \mathrm{kg}^{-1}$, which includes tax and fuel surcharge.

Equipment weight: A $10 \mathrm{~m}^{3}$ oil tank weighs $1000 \mathrm{~kg}$. A $100 \mathrm{~m}^{3}$ water tank weighs $5000 \mathrm{~kg}$. The weight of an average $100 \mathrm{~kW}$ oil boiler is $950 \mathrm{~kg}$. A $10 \%$ weight of packaging was assumed. The weight of solar panel was assumed at $20 \mathrm{~kg} \mathrm{~m}^{-2}$.

In addition to the costs stated above, the following technical and economic assumptions were made:

1. The cost of electricity consumption of the pumps withdrawing water from the lake and pumping it into the pipeline was not considered since it would be the same in BAU and BTES scenarios.

2. The cost of heating distribution was not considered.

3. Tools and parts, such as bolts and screws were considered negligible and not included.

4. The price of diesel considered in scenarios BAU, BTES 224 and BTES 37 is the real cost at $1.51 \mathrm{USD}^{-1}$. 
5. The cost of PV electricity production considered in "BTES 37 PV Subsidised" is the average LCOE described by [4] in Yukon (Canada), i.e. 0.51 USD kWh-1.

6. The cost of propylene glycol and related shipping was not considered.

7. The $\mathrm{CO}_{2}$ emissions related to transportation by boat of fuel oil and materials were not included in the calculation.

8. The cost of a monitoring system was not considered.

9. Discount rate $=6 \%$ [95].

10. Annual energy and maintenance costs escalation rates $=0 \%$.

11. Project lifetime $=50$ years. Project starts in 2020 and ends in 2069 .

12. No sudden fluctuation in the costs of electricity and diesel throughout the project life-cycle.

13. Depreciation rates of heating equipment not considered.

More details about the costs chosen for each item considered in the LCCA can be found in [96].

\section{NOMENCLATURE}

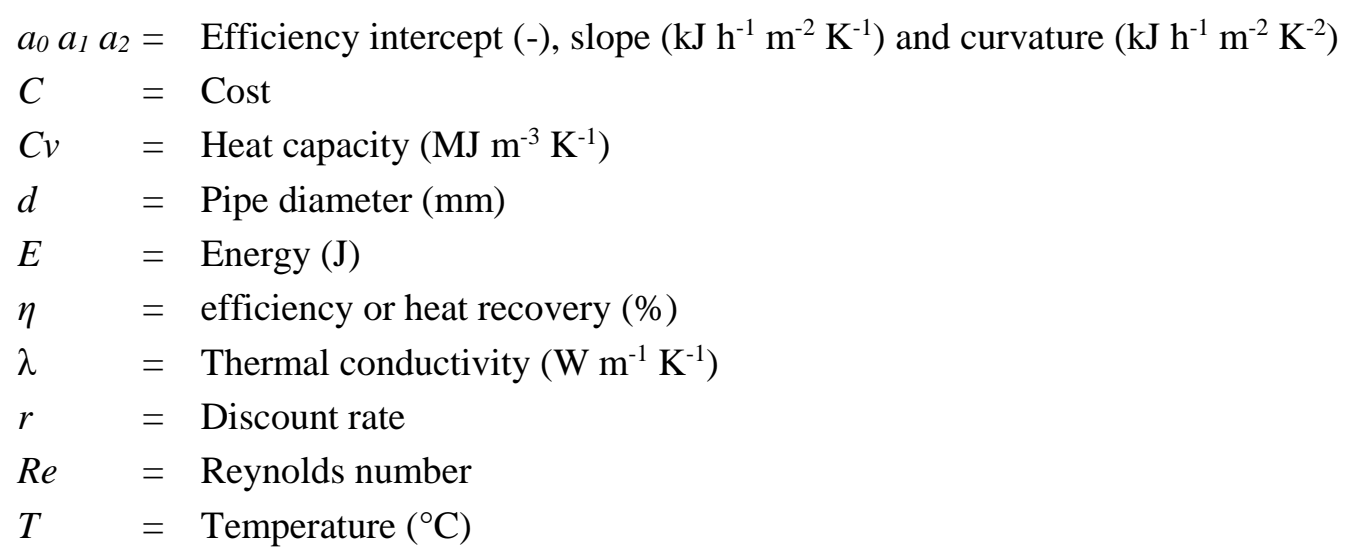

Subscripts

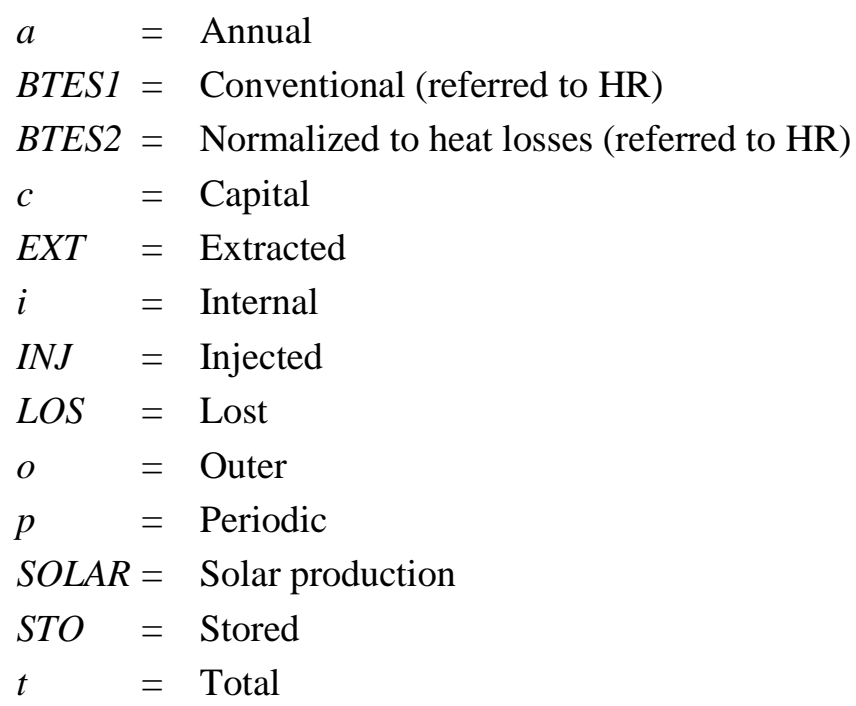

Abbreviations

$\begin{array}{ll}\mathrm{B} & =\text { Border } \\ \mathrm{BAU} & =\text { Business as usual }\end{array}$ 


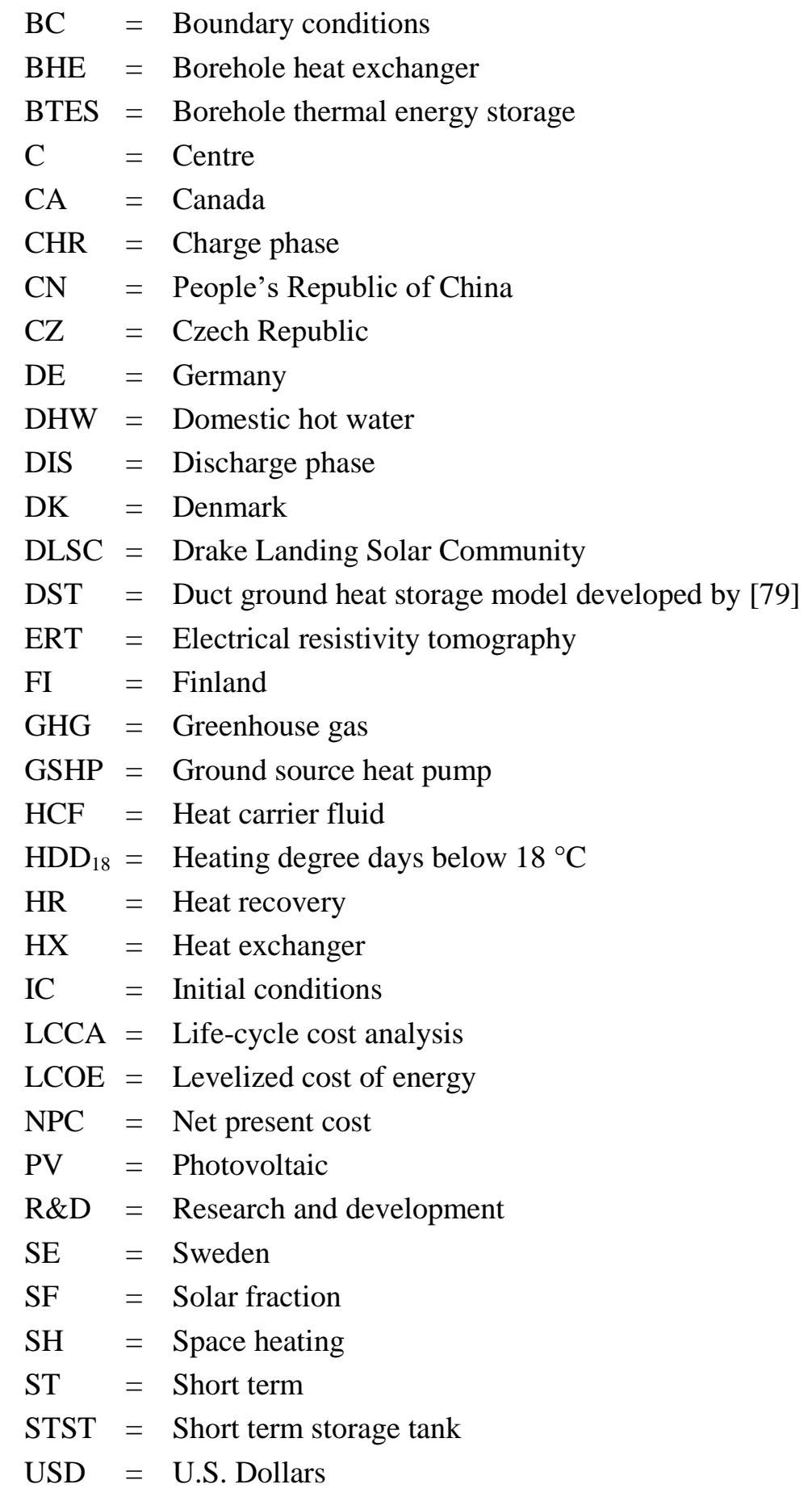

\section{REFERENCES}

[1] Funston BW. SDWG Report on Arctic Energy. 2009.

[2] Hemsath JP. The Arctic Energy Summit: Final report and technical proceeding. Anchorage, Alaska: 2010

[3] Poelzer G, Gjorv GH, Holdmann G, Johnson N, Magnússon BM, Sokka L, et al. Developing Renewable Energy in Arctic and Sub-Arctic Regions and Communities: Working Recommendations of the Fulbright Arctic Initiative Energy Group. University of Saskatchewan/International Centre for 
Northern Governance and Development; 2016.

[4] Cherniak D, Dufresne V, Keyte L, Mallett A, Schott S. Report on the State of Alternative Energy in the Arctic (Presented to Polar Knowledge Canada) 2015.

[5] Berdin VK, Kokorin AO, Yulkin GM. Renewable energy in off-grid settlements in the Russian Arctic. 2017.

[6] Energy Studies Institute. Arctic Renewable Energy Atlas (AREA) Projet: August 2018 Singapore Workshop Report. Singapore: 2018.

[7] Biskaborn BK, Smith SL, Noetzli J, Matthes H, Vieira G, Streletskiy DA, et al. Permafrost is warming at a global scale. Nat Commun 2019;10:264. doi:10.1038/s41467-018-08240-4.

[8] Hoegh-Guldberg O, Jacob D, Taylor M, Bindi M, Brown S, Camilloni I, et al. Impacts of $1.5^{\circ} \mathrm{C}$ global warming on natural and human systems. Glob. Warm. $1.5^{\circ} \mathrm{C}$. An IPCC Spec. Rep. impacts Glob. Warm. $1.5^{\circ} \mathrm{C}$ above pre-industrial levels Relat. Glob. Greenh. gas Emiss. pathways, Context Strength. Glob. response to Threat Clim. Chang., Intergovernmental Panel on Climate Change; 2018, p. 138.

[9] International Gwich'in Council. Arctic sustainable energy toolkit n.d. https://gwichincouncil.com/arctic-sustainable-energy-toolkit (accessed March 18, 2019).

[10] Royer J. Status of remote/off-grid communities in Canada. 2011.

[11] Société d'Habitation du Québec. Le Logement Au Nunavik Document D’Information. Québec City: 2014.

[12] Hydro-Québec. Réseaux autonomes - Portrait d'ensemble et perspectives d'avenir. Québec City: 2011.

[13] Karanasios K, Parker P. Recent Developments in Renewable Energy in Remote Aboriginal Communities, Quebec, Canada. In: University of Waterloo, editor. Pap. Can. Econ. Dev., Waterloo: 2016, p. 98-108. doi:10.15353/pced.v16i0.

[14] Makivik Corporation. Rise in the Cost of Gasoline 2018:1.

[15] Ministère du développement durable environnement et lutte contre les changements climatiques (MDDELCC). Plan d'action sur les changements climatiques 2013 - 2020. Québec City: 2012.

[16] Xu J, Wang RZ, Li Y. A review of available technologies for seasonal thermal energy storage. Sol Energy 2014;103:610-38. doi:10.1016/j.solener.2013.06.006.

[17] Alva G, Lin Y, Fang G. An overview of thermal energy storage systems. Energy 2018;144:341-78. doi:10.1016/j.energy.2017.12.037.

[18] Cabeza LF, Concurrent GI, Lleida U De. Thermal Energy Storage. vol. 3. Elsevier Ltd.; 2012. doi:10.1016/B978-0-08-087872-0.00307-3. 
[19] Gehlin S. 11 - Borehole thermal energy storage. In: Rees SJBT-A in G-SHPS, editor. Adv. GroundSource Heat Pump Syst., Woodhead Publishing; 2016, p. 295-327. doi:https://doi.org/10.1016/B9780-08-100311-4.00011-X.

[20] Welsch B, Göllner-Völker L, Schulte DO, Bär K, Sass I, Schebek L. Environmental and economic assessment of borehole thermal energy storage in district heating systems. Appl Energy 2018;216:7390. doi:10.1016/j.apenergy.2018.02.011.

[21] Giordano N, Comina C, Mandrone G, Cagni A. Borehole thermal energy storage (BTES). First results from the injection phase of a living lab in Torino (NW Italy). Renew Energy 2016;86. doi:10.1016/j.renene.2015.08.052.

[22] Brun G. La régularisation de l'énergie solaire par stockage thermique dans le sol. Rev Général Therm $1965 ; 44$.

[23] Dalenbäck J-O. Central solar heating plants with seasonal storage: status report. Stockholm: Swedish Council for Building Research; 1990.

[24] Hellström G. Ground heat storage, thermal analyses of duct storage systems, part I: theory (thesis). University of Lund, 1991.

[25] Hadorn JC, Saugy B. Stockage souterrain de chaleur en terre humide. Développement d'un modèle de calcul et comparaison avec des mesures in situ. Lausanne: 1981.

[26] Fisch MN, Guigas M, Dalenbäck JO. A review of large-scale solar heating systems in Europe. Sol Energy 1998;63:355-66.

[27] Schmidt T, Mangold D, Müller-Steinhagen H. Central solar heating plants with seasonal storage in Germany. Sol Energy 2004;76:165-74. doi:10.1016/j.solener.2003.07.025.

[28] Gao L, Zhao J, Tang Z. A review on borehole seasonal solar thermal energy storage. Energy Procedia 2015;70:209-18. doi:10.1016/j.egypro.2015.02.117.

[29] Sibbitt B, Mcclenahan D, Djebbar R, Thornton J, Wong B. The performance of a high solar fraction seasonal storage district heating system - five years of operation 2012;30:856-65. doi:10.1016/j.egypro.2012.11.097.

[30] Tordrup KW, Poulsen SE, Bjørn H. An improved method for upscaling borehole thermal energy storage using inverse fi nite element modelling. Renew Energy 2017;105:13-21. doi:10.1016/j.renene.2016.12.011.

[31] Giordano N, Arato A, Comina C, Mandrone G. Time-lapse electrical resistivity imaging of the thermally affected zone of a Borehole Thermal Energy Storage system near Torino (Northern Italy). J Appl Geophys 2017;140. doi:10.1016/j.jappgeo.2017.03.015. 
[32] Ciampi G, Rosato A, Sibilio S. Thermo-economic sensitivity analysis by dynamic simulations of a small Italian solar district heating system with a seasonal borehole thermal energy storage. Energy 2018;143:757-71. doi:https://doi.org/10.1016/j.energy.2017.11.029.

[33] Panno D, Buscemi A, Beccali M, Chiaruzzi C, Cipriani G, Ciulla G, et al. A solar assisted seasonal borehole thermal energy system for a non-residential building in the Mediterranean area. Sol Energy 2018. doi:https://doi.org/10.1016/j.solener.2018.06.014.

[34] Rapantova N, Pospisil P, Koziorek J, Vojcinak P, Grycz D, Rozehnal Z. Optimisation of experimental operation of borehole thermal energy storage 2016;181:464-76. doi:10.1016/j.apenergy.2016.08.091.

[35] Jacobson MZ, Mark A, Bauer ZAF, Wang J, Weiner E, Yachanin AS, et al. $100 \%$ Clean and Renewable Wind, Water, and Sunlight All-Sector Energy Roadmaps for 139 Countries of the World. Joule 2017;1:108-21. doi:10.1016/j.joule.2017.07.005.

[36] Flynn C, Siren K. Influence of location and design on the performance of a solar district heating system equipped with borehole seasonal storage. Renew Energy 2015;81:377-88. doi:10.1016/j.renene.2015.03.036.

[37] Chapuis S, Bernier M. Seasonal storage of solar energy in borehole heat exchangers. 11th Int IBSA Conf 2009:599-606.

[38] Rad FM, Fung AS, Rosen MA. An integrated model for designing a solar community heating system with borehole thermal storage. Energy Sustain Dev 2017;36:6-15. doi:10.1016/j.esd.2016.10.003.

[39] Gibb D, Johnson M, Romaní J, Gasia J, Cabeza LF, Seitz A. Process integration of thermal energy storage systems - Evaluation methodology and case studies. Appl Energy 2018;230:750-60. doi:10.1016/j.apenergy.2018.09.001.

[40] Tulus V, Boer D, Cabeza LF, Jiménez L, Guillén-Gosálbez G. Enhanced thermal energy supply via central solar heating plants with seasonal storage: A multi-objective optimization approach. Appl Energy 2016;181:549-61. doi:https://doi.org/10.1016/j.apenergy.2016.08.037.

[41] Koohi-Fayegh S, Rosen MA. Optimization of seasonal storage for community-level energy systems: status and needs. Energy, Ecol Environ 2017;2:169-81. doi:10.1007/s40974-017-0051-1.

[42] Hirvonen J, ur Rehman H, Sirén K. Techno-economic optimization and analysis of a high latitude solar district heating system with seasonal storage, considering different community sizes. Sol Energy 2018;162:472-88. doi:https://doi.org/10.1016/j.solener.2018.01.052.

[43] Elde S, Kvalvik I, Nøstvold BH, Rødbotten R, Dalmannsdottir S, Halland H, et al. The Arctic as a Food Producing Region Phase 1 : Current status in five Arctic countries. Tromsø, Norway: 2018.

[44] Lamalice A, Haillot D, Lamontagne M-A, Herrmann TM, Gibout S, Blangy S, et al. Building food 
security in the Canadian Arctic through the development of sustainable community greenhouses and gardening. Écoscience 2018;25:325-41.

[45] Stevens V, Craven C, Grunau B. Thermal storage technology assessment - An Introductory assessment of thermal storage in residential cold climate construction. 2013.

[46] Janiszewski M, Kopaly A, Honkonen M, Kukkonen I, Uotinen L, Siren T, et al. Feasibility of underground seasonal storage of solar heat in Finland. Int Conf Geo-Mechanics, Geo-Energy GeoResources Conf Proc 2016:959-65.

[47] Government of Canada. Canadian Climate Normals 1981-2010 n.d. http://climate.weather.gc.ca/climate_normals/index_e.html (accessed August 20, 2001).

[48] Leidos Canada Inc. Whistle Bend Community Solar BTES District Energy Feasibility Study Report. Whitehorse, Yukon: 2014.

[49] Chuard P, Hadorn J-C. Central solar heating plants with seasonal storage - Heat storage systems: concepts, engineering data and compilation of projects. Sorane, Switzerland: 1983.

[50] Garber-Slaght R, Craven, Colin, Peterson, Rorik, Daanen RP. Ground Source Heat Pump Demonstration in Fairbanks, Alaska 2017.

[51] You T, Wu W, Shi W, Wang B, Li X. An overview of the problems and solutions of soil thermal imbalance of ground-coupled heat pumps in cold regions. Appl Energy 2016;177:515-36. doi:10.1016/j.apenergy.2016.05.115.

[52] Fontaine PO, Marcotte D, Pasquier P, Thibodeau D. Modeling of horizontal geoexchange systems for building heating and permafrost stabilization. Geothermics 2011;40:211-20. doi:10.1016/j.geothermics.2011.07.002.

[53] Belzile P, Comeau F-A, Raymond J, Lamarche L, Carreau M. Arctic climate horizontal ground-coupled heat pump. Trans - Geotherm Resour Counc 2017;41.

[54] Casasso A, Sethi R. Efficiency of closed loop geothermal heat pumps: A sensitivity analysis. Renew Energy 2014;62:737-46. doi:10.1016/j.renene.2013.08.019.

[55] Zarrella A, Pasquier P. Effect of axial heat transfer and atmospheric conditions on the energy performance of GSHP systems: A simulation-based analysis. Appl Therm Eng 2015;78:591-604.

[56] Nguyen A, Pasquier P, Marcotte D. Borehole thermal energy storage systems under the influence of groundwater flow and time-varying surface temperature. Geothermics 2017;66:110-8.

[57] Mielke P, Bauer D, Homuth S, Götz AE, Sass I. Thermal effect of a borehole thermal energy store on the subsurface. Geotherm Energy 2014;2:1-15. 
[58] Bauer D, Heidemann W, Müller-Steinhagen H, Diersch H-JG. Modelling and simulation of groundwater influence on borehole thermal energy stores. Proc. Effstock 11th Int. Conf. Energy Storage, Stockholm: 2009, p. 8.

[59] Diersch H-JG, Bauer D, Heidemann W, Ruhaak W, Schatzl P. Finite element modeling of borehole heat exchanger systems Part 2. Numerical simulation. Comput Geosci 2011;37:1136-47. doi:10.1016/j.cageo.2010.08.002.

[60] Fortier R, Allard M, Lemieux J-M, Therrien R, Molson J, Fortier D. Cartographie des dépôts quaternaires des villages nordiques de Whapmagoostui-Kuujjuarapik, Umiujaq, Salluit et Kuujjuaq. Rapport de synthèse de la Phase 1 Stratégie de déploiement du réseau Immatsiak. Québec City: 2011.

[61] Lemieux J-M, Fortier R, Talbot-Poulin M-C, Molson J, Therrien R, Ouellet M, et al. Groundwater occurrence in cold environments: examples from Nunavik, Canada. Hydrogeol J 2016;24:1497-513. doi:10.1007/s10040-016-1411-1.

[62] Klein SA, Beckman WA, Mitchell JW, Duffie JA, Duffie NA, Freeman TL, et al. TRNSYS 18: A Transient System Simulation Program 2017.

[63] Giordano N, Kanzari I, Miranda MM, Dezayes C, Raymond J. Thermal energy storage in subarctic climates: a feasibility study conducted in Kuujjuaq (QC, Canada). In: Spitler J, Acuna J, Bernier M, Fang Z, Gehlin S, Javed S, et al., editors. IGSHPA Res. Conf. Proc., Stockholm: 2018, p. 150-9. doi:10.22488/okstate.18.000024.

[64] Diersch H-JG. FEFLOW Finite element modeling of flow, mass and heat transport in porous and fractured media. Berlin: Springer Berlin Heidelberg; 2014.

[65] Allard M, Lemay M. Nunavik and Nunatsiavut: From science to policy. An Integrated Regional Impact Study (IRIS) of climate change and modernization. Quebec City: 2012.

[66] Wardle RJ, James DT, Scott DJ, Hall J. The southeastern Churchill Province: synthesis of a Paleoproterozoic transpressional orogen. Can J Earth Sci 2002;39:639-63. doi:10.1139/e02-004.

[67] Simard M, Lafrance I, Hammouche H, Legouix C. Géologie de la région de Kuujjuaq et de la baie d’Ungava (SRNC 24J, 24K). Quebec City: Gouvernement du Québec; 2013.

[68] Giordano N, Kanzari I, Miranda MM, Dezayes C, Raymond J. Shallow geothermal resource assessments for the northern community of Kuujjuaq, Québec, Canada. IGCP636 Annu. Meet., Santiago de Chile: 2017, p. 1-4.

[69] Miranda MM, Dezayes C, Giordano N, Kanzari I, Raymond J, Carvalho J. Fracture Network Characterization as input for Geothermal Energy Research : Preliminary data from Kuujjuaq, Northern Québec , Canada. 43rd Work. Geotherm. Reserv. Eng. Stanford Univ., Stanford: 2018, p. 1-12. 
[70] Ritzema HP. Drainage principles and applications. 3rd ed. ILRI; 2006.

[71] QGIS Development Team. QGIS Geographic Information System 2018.

[72] Davis SN, DeWiest RJM. Hydrogeology. University. Ann Arbor: Wiley; 1966.

[73] Raymond J, Comeau F, Malo M, Blessent D, Jacqueline I, Sánchez L. The Geothermal Open Laboratory: a free space to measure thermal and hydraulic properties of geological materials 2017.

[74] Bélanger C, Huard D, Gratton Y, Jeong DI, St-Hilaire A, Auclair JC, et al. Impacts des changements climatiques sur l'habitat des salmonidés dans les lacs nordiques du Québec. 2013.

[75] Skarphagen H, Banks D, Frengstad BS, Gether H. Design Considerations for Borehole Thermal Energy Storage (BTES): A Review with Emphasis on Convective Heat Transfer. Geofluids 2019:1-26. doi:10.1155/2019/4961781.

[76] Pahud D. Central Solar Heating Plants With Seasonal Duct Storage and Short-Term Water Storage : Design Guidelines Obtained By Dynamic System Simulations 2000;69:495-509.

[77] Sweet ML, McLeskey JT. Numerical simulation of underground Seasonal Solar Thermal Energy Storage (SSTES) for a single family dwelling using TRNSYS. Sol Energy 2012;86:289-300. doi:10.1016/j.solener.2011.10.002.

[78] Terziotti LT, Sweet ML, McLeskey JT. Modeling seasonal solar thermal energy storage in a large urban residential building using TRNSYS 16. Energy Build 2012;45:28-31. doi:10.1016/j.enbuild.2011.10.023.

[79] Hellström G. Duct Ground Heat Storage Model, Manual for Computer Code. Swedish Council for Building Research (BFR) and National Energy Administration; 1989.

[80] Reuss M, Beck M, Müller JP. Design of a seasonal thermal energy storage in the ground. Sol Energy 1997;59:247-57.

[81] Di Sipio E, Galgaro A, Destro E, Teza G, Chiesa S, Giaretta A, et al. Subsurface thermal conductivity assessment in Calabria (southern Italy): a regional case study. Environ Earth Sci 2014;72:1383-401. doi:10.1007/s12665-014-3277-7.

[82] PlanEnergi. Boreholes in Braedstrup - Final report. Braedstrup, DK: 2013.

[83] Bauer D, Heidemann W, Muller-Steinhagen H, Diersch HJG. Thermal resistance and capacity models for borehole heat exchangers. Int J Energy Res 2011;35:312-20. doi:10.1002/er.1689.

[84] Eskilson P, Claesson J. Simulation model for thermally interacting heat extraction boreholes. Numer Heat Transf 1988;13:149-65. doi:10.1080/10407788808913609.

[85] Al-Khoury R, Bonnier PG, Brinkgreve RBJ. Efficient finite element formulation for geothermal heating 
systems . Part I : Steady state. Int J Numer Methods Eng 2005;63:988-1013. doi:10.1002/nme.1313.

[86] Al-Khoury R, Bonnier PG. Efficient finite element formulation for geothermal heating systems . Part II : Transient. Int J Numer Methods Eng 2006;67:725-45. doi:10.1002/nme.1662.

[87] Anbergen H, Rühaak W, Frank J, Sass I. Numerical simulation of a freeze - thaw testing procedure for borehole heat exchanger grouts. Can Geotech J 2015;52:1-14.

[88] Xu J, Li Y, Wang RZ, Liu W. Performance investigation of a solar heating system with underground seasonal energy storage for greenhouse application. Energy 2014;67:63-73. doi:10.1016/j.energy.2014.01.049.

[89] Hydro-Québec. Plan d’approvisionnement 2017-2026. Réseaux autonomes. 2016.

[90] Belzile P, Comeau F-A, Raymond J, Lamarche L. Revue technologique : efficacité énergétique et énergies renouvelables au nord du Québec 2017:38.

[91] Zhang L, Xu P, Mao J, Tang X, Li Z, Shi J. A low cost seasonal solar soil heat storage system for greenhouse heating: Design and pilot study. Appl Energy 2015;156:213-22. doi:10.1016/j.apenergy.2015.07.036.

[92] Bourbonnais M, Déry P, Nadeau Y, Savard G, Pagé M, Duval M. Optimisation d'un chauffe-eau solaire thermique air-liquide: Essais et étude des performances comparatives en situation réelle avec un chauffe-eau solaire standard au glycol. ASHRAE Chapitre Québec 2017;40:4-9.

[93] Bourbonnais M, Déry P. Le chauffe-eau solaire photovoltaïque (PV). Une option prometteuse pour le développement du solaire au Québec? Électricité Québec 2018;65:8-20.

[94] Régie Régionale De La Santé Et Des Services Sociaux Nunavik n.d. https://ca.indeed.com/cmp/RégieRégionale-De-La-Santé-Et-Des-Services-Sociaux-

Nunavik/salaries?job_category=install\&location=CA\%2FQC\%2FKuujjuaq (accessed May 6, 2019).

[95] Thornton G. Renewable energy discount rate survey results - 20172017.

[96] Gunawan E. Alternative heating systems for northern remote communities: Techno-economic analysis of ground-source heat pumps in Kuujjuaq, Nunavik, Canada. Reykjavik University, 2019. 


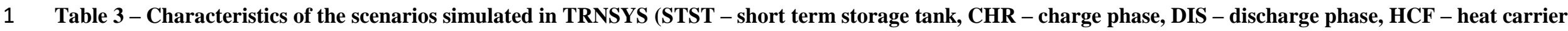

2 fluid). Shape factor is calculated as the depth-to-diameter ratio.

\begin{tabular}{|c|c|c|c|c|c|c|c|c|c|c|c|}
\hline & SC1 & $\mathrm{SC2}$ & $\mathrm{SC3}$ & SC4 & SC5 & SC6 & SC7 & SC8 & SC9 & SC10 & SC11 \\
\hline Number of BHE (-) & 100 & 100 & 100 & 100 & 100 & 50 & 50 & 100 & 150 & 100 & 100 \\
\hline Gross solar area $\left(\mathbf{m}^{2}\right)$ & 1000 & 1000 & 1000 & 1000 & 1000 & 1000 & 1000 & 1500 & 1500 & 1000 & 1000 \\
\hline Number of STST (-) & 1 & 2 & 2 & 2 & 2 & 2 & 2 & 2 & 2 & 2 & 2 \\
\hline BTES volume (m³) & 22000 & 22000 & 9500 & 22000 & 22000 & 9500 & 22000 & 22000 & 35000 & 22000 & 22000 \\
\hline BHE spacing (m) & 2.9 & 2.9 & 1.9 & 2.9 & 2.9 & 2.7 & 4.1 & 3 & 3 & 3 & 3 \\
\hline Shape factor (-) & 1 & 1 & 1.5 & 1 & 1 & 1.5 & 1 & 1 & 0.8 & 1 & 1 \\
\hline Use of cold STST (-) & - & CHR/DIS & CHR/DIS & DIS & CHR/DIS & CHR/DIS & CHR/DIS & CHR/DIS & CHR/DIS & CHR/DIS & CHR/DIS \\
\hline Pre-heating period (y) & 0 & 0 & 0 & 0 & 1 & 0 & 0 & 0 & 0 & 0 & 0 \\
\hline Preheating $T\left({ }^{\circ} \mathbf{C}\right)$ & - & - & - & - & 10 & - & - & - & - & - & - \\
\hline Glycol in HCF (\% vol.) & 50 & 50 & 50 & 50 & 50 & 50 & 50 & 50 & 50 & 25 & 50 \\
\hline Flow rate in BTES $\left(\mathrm{m}^{3} \mathrm{~h}^{-1}\right)$ & 40 & 40 & 40 & 40 & 40 & 40 & 40 & 40 & 60 & 40 & 60 \\
\hline$R e$ in BHE (-) & 1400 & 1400 & 1400 & 1400 & 1400 & 2800 & 2800 & 1400 & 1400 & 4400 & 2100 \\
\hline
\end{tabular}

3

4 Table 5 - Summary of the TRNSYS simulations during year 3 (from 19680 to 28440 h).

\begin{tabular}{|c|c|c|c|c|c|c|c|c|c|c|c|c|c|c|c|c|}
\hline & \multirow{2}{*}{\multicolumn{2}{|c|}{$\begin{array}{c}\text { Solar Energy } \\
\text { Production } \eta_{\text {SOLAR }}\end{array}$}} & \multirow{2}{*}{\multicolumn{2}{|c|}{ STST Losses }} & \multicolumn{4}{|c|}{ CHARGE } & \multicolumn{3}{|c|}{ DISCHARGE } & \multicolumn{5}{|c|}{ Pumping Station } \\
\hline & & & & & Injection & Lo & & Storage & Extraction & $\eta_{\text {BTES1 }}$ & $\eta_{\text {BTES2 }}$ & BTES & STST & BTES+STST & SF & Aux. \\
\hline & GJ & $\%$ & GJ & $\%$ & GJ & GJ & $\%$ & GJ & GJ & $\%$ & $\%$ & MWh & MWh & MWh & $\%$ & MWh \\
\hline SC1 & 963.1 & 31.5 & 30.5 & 3.2 & 932.6 & 268.2 & 28.8 & 664.5 & 465.2 & 49.9 & 70.0 & 129.2 & 11.6 & 140.8 & 35.2 & 259.2 \\
\hline $\mathrm{SC2}$ & 962.8 & 31.5 & 34.0 & 3.5 & 928.8 & 246.2 & 26.5 & 682.6 & 527.1 & 56.8 & 77.2 & 146.4 & 22.5 & 168.9 & 42.2 & 231.1 \\
\hline $\mathrm{SC3}$ & 800.6 & 26.2 & 45.7 & 5.7 & 754.9 & 257.1 & 34.1 & 497.8 & 473.0 & 62.6 & 95.0 & 131.4 & 20.7 & 152.0 & 38.0 & 248.0 \\
\hline SC4 & 966.8 & 31.6 & 24.2 & 2.5 & 942.6 & 251.5 & 26.7 & 691.1 & 534.8 & 56.7 & 77.4 & 148.6 & 21.3 & 169.9 & 42.5 & 230.1 \\
\hline SC5 & 940.4 & 30.8 & 24.9 & 2.6 & 915.5 & 234.9 & 25.7 & 680.6 & 560.3 & 61.2 & 82.3 & 155.6 & 21.1 & 176.7 & 44.2 & 223.3 \\
\hline SC6 & 652.5 & 21.4 & 48.3 & 7.4 & 604.2 & 196.7 & 32.6 & 407.5 & 341.5 & 56.5 & 83.8 & 94.9 & 24.4 & 119.3 & 29.8 & 280.7 \\
\hline SC7 & 736.0 & 24.1 & 41.4 & 5.6 & 694.5 & 191.6 & 27.6 & 503.0 & 314.8 & 45.3 & 62.6 & 87.4 & 24.1 & 111.6 & 27.9 & 288.4 \\
\hline SC8 & 1109.6 & 24.2 & 46.8 & 4.2 & 1062.8 & 283.8 & 26.7 & 779.0 & 614.0 & 57.8 & 78.8 & 170.5 & 26.5 & 197.0 & 49.3 & 203.0 \\
\hline SC9 & 1360.3 & 29.7 & 31.7 & 2.3 & 1328.5 & 334.4 & 25.2 & 994.1 & 719.5 & 54.2 & 72.4 & 199.9 & 27.1 & 227.0 & 56.7 & 173.0 \\
\hline SC10 & 977.3 & 32.0 & 34.1 & 3.5 & 943.2 & 241.9 & 25.6 & 701.3 & 558.4 & 59.2 & 79.6 & 155.1 & 23.3 & 178.4 & 44.6 & 221.6 \\
\hline
\end{tabular}


\begin{tabular}{l|l}
31.0 & 26.3
\end{tabular}

\begin{tabular}{l|l}
2.8 & 919.5
\end{tabular}

$\begin{array}{lll}247.3 & 26.9 & 672.3\end{array}$

513.0

55.8

76.3

$142.5 \quad 25.1$

167.6

$41.9 \quad 232.4$

6 Table 6 -Summary of the SC2 simulation results obtained with TRNSYS from year 1 to 4.

\begin{tabular}{|c|c|c|c|c|c|c|c|c|c|c|c|c|c|c|c|c|}
\hline & \multicolumn{2}{|c|}{ Solar Energy } & \multirow{2}{*}{\multicolumn{2}{|c|}{ STST Losses }} & \multicolumn{4}{|c|}{ CHARGE } & \multicolumn{3}{|c|}{ DISCHARGE } & \multicolumn{5}{|c|}{ Pumping Station } \\
\hline & Production & $\eta_{\text {SOLAR }}$ & & & Injected & & & Storage & Extraction & $\eta_{\text {BTES1 }}$ & $\eta_{\text {BTES2 }}$ & BTES & STST & BTES+STST & SF & Aux. \\
\hline & GJ & $\%$ & GJ & $\%$ & GJ & GJ & $\%$ & GJ & GJ & $\%$ & $\%$ & MWh & MWh & MWh & $\%$ & MWh \\
\hline Year 1* & 1187.0 & 32.6 & 24.4 & 2.0 & 1162.6 & 256.0 & 22.0 & 906.6 & 376.6 & 32.4 & 41.5 & 104.6 & 23.9 & 128.5 & 32.1 & 271.5 \\
\hline Year 2 & 1007.7 & 33.0 & 32.6 & 3.2 & 975.1 & 262.0 & 26.9 & 713.1 & 492.6 & 50.5 & 69.1 & 136.8 & 22.9 & 159.8 & 40.0 & 240.2 \\
\hline Year 3 & 962.8 & 31.5 & 34.0 & 3.5 & 928.8 & 246.2 & 26.5 & 682.6 & 527.1 & 56.8 & 77.2 & 146.4 & 22.5 & 168.9 & 42.2 & 231.1 \\
\hline Year 4 & 946.3 & 30.9 & 34.5 & 3.6 & 911.8 & 237.3 & 26.0 & 674.6 & 542.1 & 59.5 & 80.4 & 150.6 & 22.4 & 172.9 & 43.2 & 227.1 \\
\hline
\end{tabular}

